\title{
Acoustic and Microseismic Characterization in Steep Bedrock Permafrost on Matterhorn $(\mathrm{CH})$
}

\section{Journal Article}

\section{Author(s):}

Weber, Samuel (D); Faillettaz, Jérome; Meyer, Matthias (D); Beutel, Jan (D); Vieli, Andreas

Publication date:

2018-07-11

Permanent link:

https://doi.org/10.3929/ethz-b-000271447

Rights / license:

In Copyright - Non-Commercial Use Permitted

Originally published in:

Journal of Geophysical Research: Earth Surface 123(6), https://doi.org/10.1029/2018jf004615 


\section{Journal of Geophysical Research: Earth Surface}

\section{RESEARCH ARTICLE}

10.1029/2018JF004615

Key Points:

- Over 2 years of acoustic and

microseismic activity in the range of

$1-10^{5} \mathrm{~Hz}$ has been acquired in steep

fractured bedrock permafrost

- Observed waveform characteristics

strongly depend on propagation

distance and thus do not allow feature

detection by cross correlation

- An amplification between 33 and

$67 \mathrm{~Hz}$ was observed and allows

improved detection of fracture events

in this frequency band

Supporting Information:

- Supporting Information S1

Correspondence to:

S. Weber,

samuel.weber@geo.uzh.ch

Citation:

Weber, S., Faillettaz, J., Meyer, M.

Beutel, J., \& Vieli, A. (2018).

Acoustic and microseismic

characterization in steep

bedrock permafrost on Matterhorn

(CH). Journal of Geophysical

Research: Earth Surface, 123.

https://doi.org/10.1029/2018JF004615

Received 13 FEB 2018

Accepted 16 MAY 2018

Accepted article online 24 MAY 2018

(C)2018. American Geophysical Union All Rights Reserved.

\section{Acoustic and Microseismic Characterization in Steep Bedrock Permafrost on Matterhorn (CH)}

\author{
Samuel Weber ${ }^{1}$ iD, Jérome Faillettaz ${ }^{1}$, Matthias Meyer $^{2}{ }^{D}$, Jan Beutel ${ }^{2}$ iD, and Andreas Vieli ${ }^{1}$ \\ ${ }^{1}$ Department of Geography, University of Zurich, Zurich, Switzerland, ${ }^{2}$ Computer Engineering and Networks Laboratory, \\ ETH Zurich, Zurich, Switzerland
}

Abstract Understanding of processes and factors influencing slope stability is essential for assessing the stability of potentially hazardous slopes. Passive monitoring of acoustic emissions and microseismology provides subsurface information on fracturing (timing and identification of the mechanism) and therefore complement surface displacement data. This study investigates for the first time acoustic and microseismic signals generated in steep, fractured bedrock permafrost, covering the broad frequency range of $1-10^{5} \mathrm{~Hz}$. The analysis of artificial forcing experiments using a rebound hammer in a controlled setting led to two major findings: First, statistically insignificant cross correlation between signals indicates that waveforms change strongly with propagation distance. Second, a significant amplification is found in the frequency band $33-67 \mathrm{~Hz}$. This finding is strongly supported by evidence from artificial rockfall events and more importantly by naturally occurring fracture events identified in fracture displacement data. Thus, filtering this frequency band enables enhanced detection of microseismic events relevant for slope stability assessment. The analysis of 2-year time series in this frequency band further suggests that the detected energy rate baseline of all automatically triggered events using the STA/LTA algorithm is not sensitive to temperature forcing, an observation of primary importance for long-term data collection, analysis, and interpretation. The event detection in the established frequency band is not only improved but also not affected by the short- and long-term temperature changes in such a rapidly changing environment.

\section{Introduction}

Rock slope failure is a significant hazard potentially posing a risk for people and infrastructure. While rock slope failure is in general related to fracture of cohesive rock bridges and the overcoming of frictional resistance within different material combinations (Erismann \& Abele, 2001), permafrost can be an important transient element subjected to fast change (Gruber \& Haeberli, 2007). The formation of ice induces pressure variations in rock pores and cracks at a sufficient level to fracture intact high-porosity rocks (Murton et al., 2006). Therefore, cryostatic pressure is an important driver of rock fracturing and can arise from ice expansion or ice segregation (Matsuoka \& Murton, 2008). The presence of permafrost and its associated freeze-thaw cycles can lead to an increase in shear stress due to (i) a change in water or cryostatic pressure and (ii) a decrease of shear resistance by altering the mechanical behavior of intact rock, rock-rock contacts, rock-ice contacts, and interstitial ice (Krautblatter et al., 2013).

Detecting and monitoring rock slope instabilities as they progress toward final failure are key to the understanding of failure mechanisms (Eberhardt et al., 2008) and offer new opportunities for effective early warning (Stähli et al., 2015). Precursory displacements or small failures in advance of the final full failure are the result of internal failure processes such as fracture propagation or sliding (Eberhardt et al., 2004; Petley, 2004). Measuring relative surface displacements and spatial patterns are common approaches to monitor kinematic properties aiming to identify environmental forcing (Blikra \& Christiansen, 2014; Draebing et al., 2017; Hasler et al., 2012; Matsuoka \& Murton, 2008; Nordvik et al., 2010; Weber et al., 2017; Wegmann \& Gudmundsson, 1999). However, the separation of distinct patterns that are indicative of progression toward a rock slope failure from background processes often remains difficult if not impossible, because each point measurement is dominated by local effects rather representing the general behavior of the whole slope (Rosser et al., 2007). In general, stability assessment based on surface displacement measurements has two main disadvantages: (1) substantial movement does not necessarily lead to catastrophic collapse (Szwedzicki, 2003) and (2) surface displacement data may provide little or no data with respect to rock slope instability 
at depth (Arosio et al., 2009). Rosser et al. (2007) suggested that spatial and temporal patterns in rockfall activity, identified by three-dimensional laser scanning, can potentially be viewed and quantified as precursory behavior prior to slope failure. The laser scanning approach provides constraints on the location and released volume of rock but delivers limited information on rockfall triggering mechanisms and the dynamics (i.e., detachment, fall, impact, and disintegration) of individual events (Dietze et al., 2017). In contrast, passive monitoring of acoustic emission (AE) and microseismic (MS) activity addresses these shortcomings as the emission signals captured provide information with respect to fracture processes ongoing within a delimited perimeter. However, it can provide only limited information on the location and volume of a potential release. Furthermore, analyzing such signals presents significant challenges, since it is dependent first on the nature and positioning of sensors, second on attenuation of signals in the rock mass under observation, and third on the superimposed ambient noise.

So far, the ability to detect fracture events based on AE/MS measurements in steep bedrock permafrost is largely unexplored outside of laboratory settings and the appropriate frequency range relevant for fracture detection in a full-scale outdoor environment remains unclear, limiting our ability to deploy suitable systems with the highest event detection probability. This study focuses on filling this void aiming to characterize the propagation of AE/MS signals to facilitate fracture event detection in such media on an actual field site. The detailed understanding of the relevant processes at scale and in a real target environment is a prerequisite for future research on processes of fracture initiation and mechanisms leading to failure. Before outlining the aim and objective of this study in detail, we provide an overview of existing research of AE/MS in rock slopes and permafrost and give the theoretical background on signal propagation and attenuation in such media.

\subsection{Acoustic Emissions and Microseismic Measurements}

Acoustic emissions and microseismic signals are elastic waves generated by the rapid release of energy within a material (Hardy, 2003), mostly caused by mechanical loading and related to an increase in material damage (Lockner et al., 1991; Scholz, 1968), such as crack formation, fracture propagation, failure of intact rock bridges, friction between rock blocks, or grain motion/rearrangements in granular materials. Detection of AE and MS are not distinct techniques, but are usually referring to different frequency domains: $A E$ refers to acoustic signals in the higher sonic and ultrasonic range: $1 \mathrm{kHz}$ to $1 \mathrm{MHz}$ (Ohnaka \& Mogi, 1982). AE is often measured with piezoelectric sensors and allows analysis of microfracturing in diverse materials. It has a very limited spatial observation range (centimeters to meters) due to the strong signal attenuation of high frequencies in heterogeneous materials (Dixon et al., 2003). MS refers to much smaller event intensities (microearthquake) and observation range (meters to kilometers) than conventional seismology with signals in the broad infrasonic and lower hearing range of $10^{-3}-10^{2} \mathrm{~Hz}$ (Podolskiy \& Walter, 2016). In this manuscript, we use MS in the range of $1-10^{3} \mathrm{~Hz}$ and $\mathrm{AE}$ in the range of $10^{4}-10^{6} \mathrm{~Hz}$ according to the definition of Amitrano et al. (2012).

AE/MS studies can be distinguished along three main criteria, namely, the number of stations (single station versus network installation), the duration of recording (short-term snapshot versus long-term monitoring), and type of analysis (continuous versus event-based). The detection of AE and MS activity is a powerful nondestructive analysis technique, able to give continuous insights into local irreversible (nonelastic) deformation processes due to mechanical loading of rocks (Grosse \& Ohtsu, 2008), for example, formation and progression of microcracks, friction processes, fracturing, or slips of rock masses and rockfall. Hence, AE and MS appear to be an efficient way to monitor the progression of damage with a wide range of possible applications at different scales (Michlmayr et al., 2012), such as studies in mines detecting MS emissions in rock (Obert, 1977) or AE in laboratory rock fracture experiments (Lockner, 1993). Sensing and interpreting MS activity is one of the most promising approaches to monitoring failure development continuously in time over an entire slope or rock mass (Amitrano et al., 2005, 2010; Dixon et al., 2003; Got et al., 2010; Lévy et al., 2010; Spillmann et al., 2007), in a hanging glacier (Faillettaz et al., 2008, 2011) or in a steep snowpack (Reiweger et al., 2015; Van Herwijnen \& Schweizer, 2011). The AE approach has been applied to landslide deformation characterization using a waveguide (Dixon et al., 2003, 2015; Smith et al., 2017; Zoppè et al., 2015), to frozen rock in lab studies (e.g., Duca et al., 2014; Hallet et al., 1991; Mamot et al., 2018; Murton et al., 2016) and most recently at locale scales to mountain permafrost (e.g., Amitrano et al., 2012; Girard et al., 2013; Weber et al., 2012). So far, simultaneous recording of $A E$ and $M S$ has technically not been realized (Amitrano et al., 2012) as it requires a combination of different sensor types with individual data acquisition systems. 
Many studies investigated the theoretical existence of seismic precursors prior to catastrophic failure in heterogeneous media (Alava et al., 2006; Cohen et al., 2009; Faillettaz \& Or, 2015; Faillettaz et al., 2016; Hidalgo et al., 2002; Kun et al., 2003; Pradhan et al., 2005, 2010). Experimental field evidence at slope scale are rare and limited to specific sites: For example, Amitrano et al. (2005) identified a power law acceleration of energy release and seismic rate $2 \mathrm{hr}$ prior to a chalk cliff collapse on the Normandy ocean shore (Western France). Faillettaz et al. (2011) also identified seismic precursory signs of the imminent catastrophic failure of a hanging glacier located on the east face of the Weisshorn (Valais, Switzerland). However, the potential to detect such precursory signs has not been investigated yet in bedrock permafrost. The large spatial and temporal heterogeneity in rock thermal conditions as well as in rock physical properties (e.g., fracture state, moisture content, thermal, and hydraulic conductivity) constitute a significant challenge in understanding the process of rock damage (Girard et al., 2012) and in producing methods that are widely transferable rather than site specific. An improved understanding of these processes is a prerequisite for the robust transfer of theoretical insight to field investigations, for slope stability assessments or design of early warning systems.

Recent theoretical considerations based on simple numerical modeling pointed out that the attenuation phenomenon experienced by seismic waves traveling in natural material can lead to misleading interpretation of the statistical properties of the signal amplitude (Faillettaz \& Or, 2015). Therefore, a good understanding and characterization of this phenomenon is required when investigating the AE/MS signals captured in a natural heterogeneous medium.

\subsection{Wave Propagation and Attenuation in Fractured Bedrock}

The recorded amplitude $A(d)$ of an elastic wave depends on the characteristics of the source (size and frequency components) with amplitude $A_{0}$, the signal propagation (travel path with distance $d$ ), and the nature of the sensor with its coupling to the medium. As the amplitude of a stress wave is proportional to the square root of the energy per unit area, the energy decreases due to geometric spreading $G(d)$ and internal friction (Hardy, 2003). The overall loss of signal amplitude is denoted as attenuation and a simplified expression for waves traveling directly from a point source to the receiver (Dobrin, 1960) is given as

$$
A(d)=A_{0} \cdot G(d) \cdot e^{-\alpha(f) d},
$$

where $G(d)$ is $1 / d$ for a wave of spherical type. The internal friction, given by the frequency-dependent attenuation $\alpha(f)$ and the distance $d$, describes the inelastic response of the medium, which leads to absorption or loss of energy. In addition to geometric spreading and internal friction, the effect of scattering may lead to an additional energy loss when a wave undergoes reflection and follows a ray path of length $r(d)$ (Peters et al., 2012)

$$
A(d)=A_{0} \cdot R(d) \cdot G(d) \cdot e^{-\alpha(f) r(d)}
$$

where $R(d)$ is the reflectivity at a subsurface horizon. The scattering phenomenon leads to attenuation by the generation of secondary waves spreading out in different directions when the wavelengths $\lambda$ of the incident stress wave is comparable in dimensions to the mean grain diameter (Hardy, 2003). This effect is often negligible in field observations as normally low frequencies are involved, unless the wavelength $\lambda$ of the stress wave, given by the ratio between propagation velocity $C$ (e.g., 2,700-5,200 m/s for gneiss) and frequency $f$, and block dimension are of similar length (Hardy, 2003). Moreover, the characteristics of an elastic wave propagating through a boundary or interface are modified in response to the differences in the acoustic impedance (defined as the product of the material's density and wave velocity) of the materials on either side of that boundary (Hardy, 2003). If the incident wave strikes the boundary at an oblique angle an additional phenomenon, known as mode conversion, may also occur causing the generation of refracted and reflected components and thus effectively reducing the level of stress wave amplitude and outgoing energy (Rinehart, 1975).

Wave attenuation in a rock mass restricts the detection of AE to approximately $1 \mathrm{~m}$, whereas MS can be detected over larger distances (up to kilometers; Amitrano et al., 2012). Although interest in applying AE or MS during the last decade has increased, so far, studies in steep, fractured permafrost are rare and the analysis of empirical data on AE and MS, including wave propagation and attenuation, is limited.

\subsection{Aim of This Study}

The Matterhorn Hörnligrat field site, Mattertal (Swiss Alps), has been under investigation for several years (Hasler et al., 2008, 2012, 2011) in response to a slope failure with a rock volume of approximately $1,500 \mathrm{~m}^{3}$ 


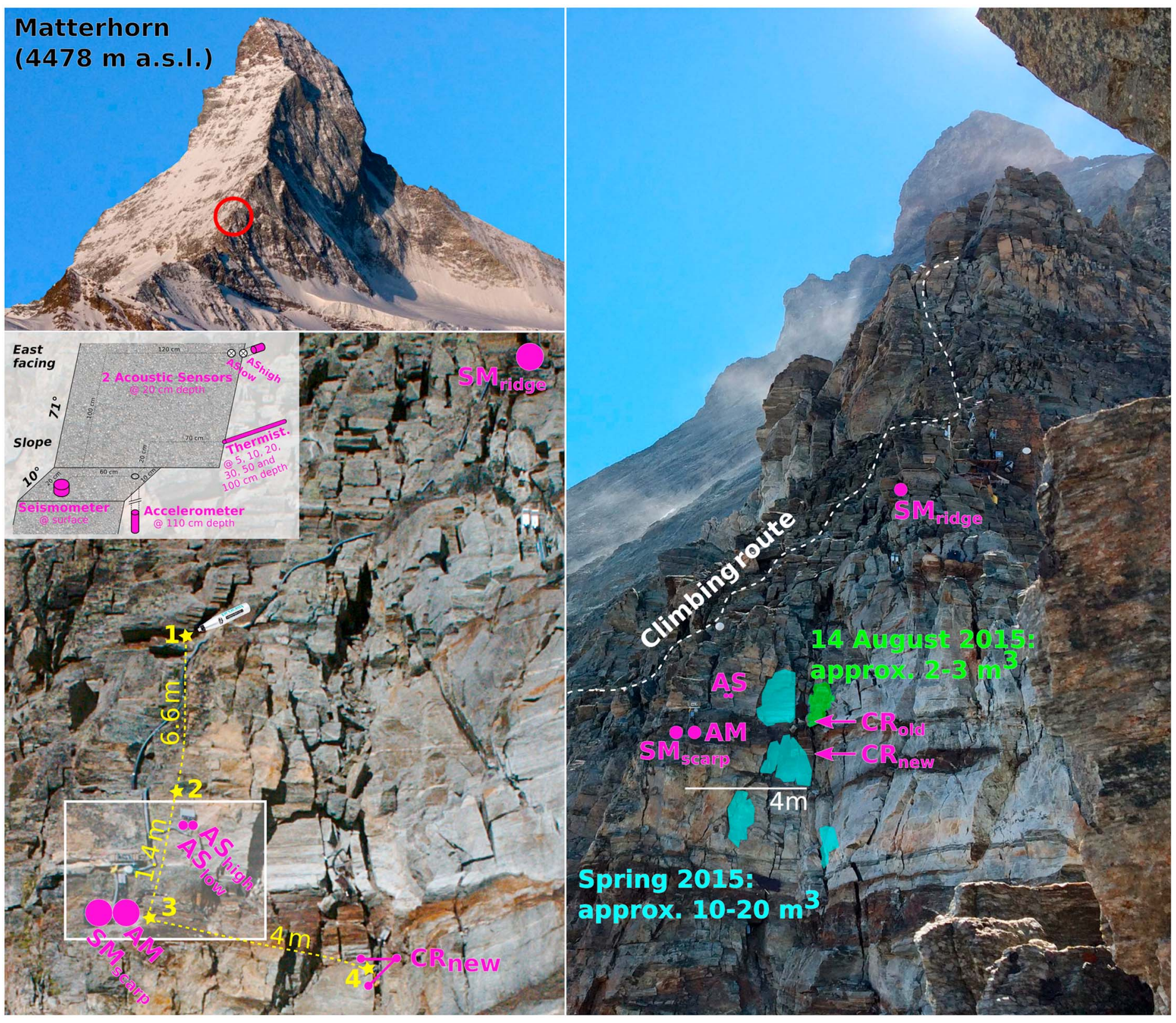

Figure 1. Detailed view of the Hörnligrat field site on the northeast ridge of the Matterhorn in the Swiss Alps at an elevation of 3,500 $\mathrm{m}$ asl with an average slope $>60^{\circ}$ (an aerial view and two cumulative zoom-in views). Mass loss due to rock fall is marked with green and cyan. Instrumentation setup for measuring acoustic ( $A S=$ acoustic sensor), microseismic ( $S M=$ seismometer; $A M=$ accelerometer), and fracture displacement $(C R=$ crackmeter with displacement directions) are indicated in pink. Crackmeter $\mathrm{CR}_{\text {old }}$ refers to $m h 02$ in Weber et al. (2017), which was lost due to a break off of the instrumented rock on 14 August 2015 . The replacement instrumentation labeled with $\mathrm{CR}_{\text {new }}$ (installed in spring 2016) consists of two crackmeters to calculate displacements perpendicular to and along fracture. A schematic zoom-in of the AE/MS instrumentation in the scarp is shown in the white box. The yellow stars show the locations of the artificial events generated by the rebound hammer method.

in summer 2003. Several rockfall events (total volume of $\sim 10-20 \mathrm{~m}^{3}$ ) were observed at Matterhorn Hörnligrat field site in spring 2015 using a time lapse camera (detachment area is marked in Figure 1). Consequently, in this study the existing fracture displacement and thermal condition monitoring (Weber et al., 2017) have been complemented by continuous broadband AE/MS monitoring in early summer 2015 . A rockfall event $\left(2-3 \mathrm{~m}^{3}\right)$ occurred on 14 August 2015. The AE/MS response to this failure and two preceding fracture displacements indicated frequency and sensor-positioning-dependent characteristics (Figure 2). Therefore, this study aims to better understand the characteristics and propagation of $A E / M S$ signals in steep, fractured bedrock permafrost and addresses two main questions related to this environment. How do the characteristics (waveform 
(a)

Fracture displacement measured at $\mathbf{C R}_{\text {old }}$ (accuracy $<0.01 \mathbf{m m}$ )

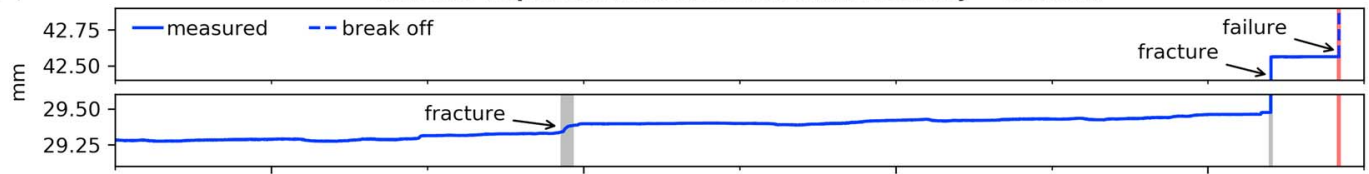

(b)

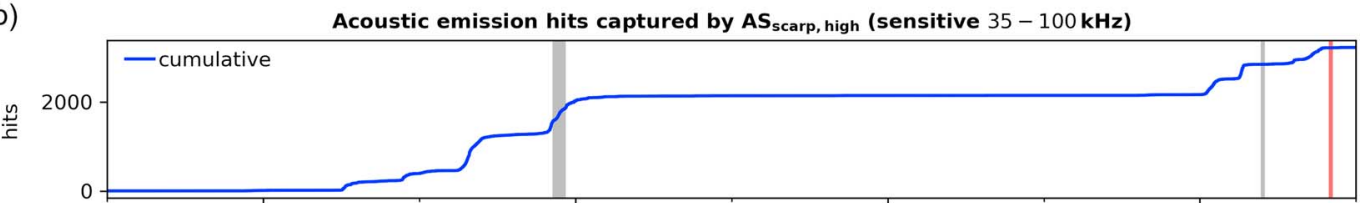

(c)

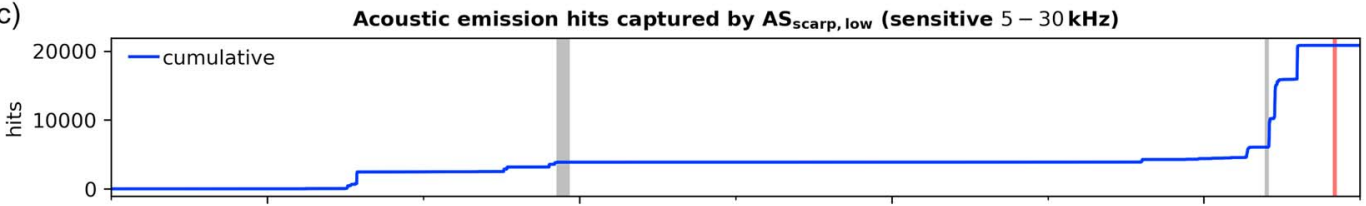

(d)

Signal captured by accelerometer $\mathbf{A M}_{\text {scarp }}$ (sensitive $10-10^{4} \mathrm{~Hz}$ )

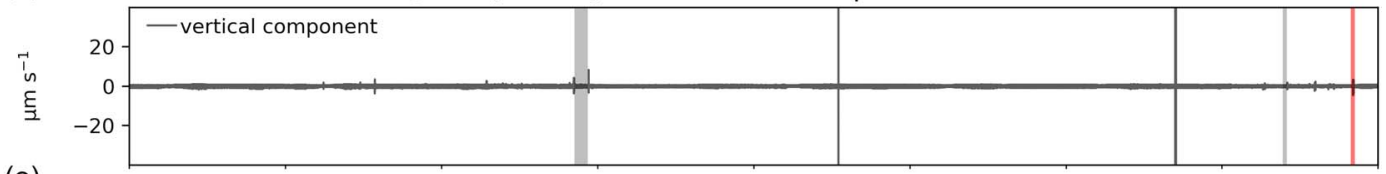

(e)

Signal captured by seismometer $\mathrm{SM}_{\text {scarp }}\left(\right.$ sensitive $1-10^{2} \mathrm{~Hz}$ )

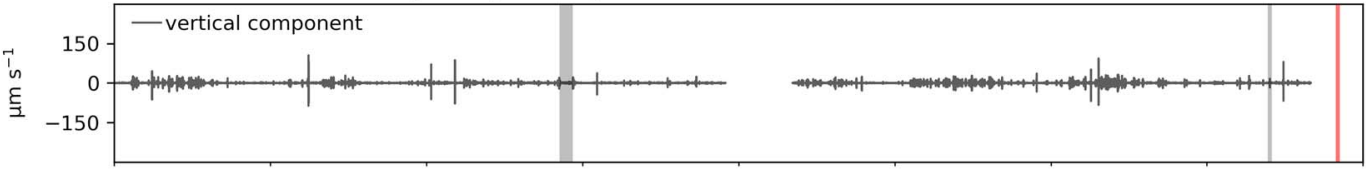

(f)

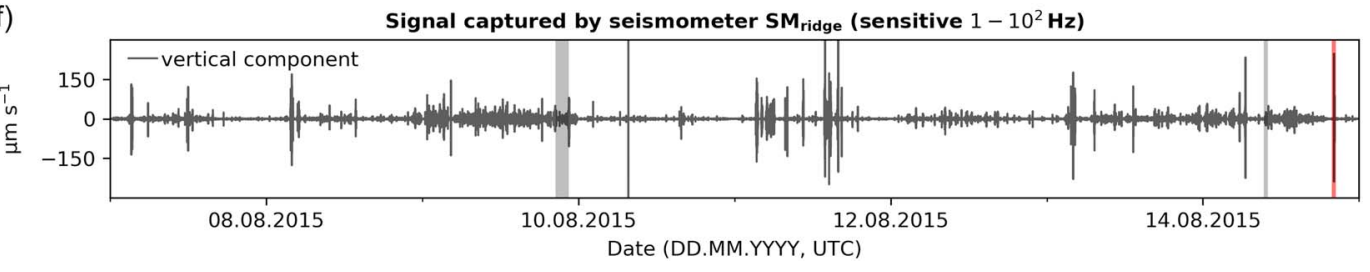

Figure 2. Simultaneous crackmeter and AE/MS records during an 8-day period preceding the rockfall event on 14 August 2015 UTC 20:10 (indicated with vertical, red line). Gray vertical bars mark two fracture displacement events. $A E$ hits are visualized cumulatively ( $b$ and $c$ ). The waveforms of the vertical component in velocity are plotted for the accelerometer (d) and the seismometers in the scarp (e) and on the ridge (f). For related time lapse camera pictures, see Figure $\mathrm{S} 1$ in the supporting information.

and energy spectral density) of elastic waves in the frequency range of $1-10^{5} \mathrm{~Hz}$ change as they propagate? What are possible implications on fracture detection in different frequency domains?

To our knowledge, only a few studies using either AE or MS technique have been carried out in fractured bedrock permafrost (Amitrano et al., 2012, 2010; Girard et al., 2013; Occhiena et al., 2012), but none has covered the entire broadband frequency range of $1-10^{5} \mathrm{~Hz}$ in such an environment. This is important so as to determine the appropriate frequency range relevant for fracture detection. In addition, propagation characteristics of $A E / M S$ signals are poorly understood in such media and extreme environments.

In this manuscript, we present a novel instrumentation setup to measure AE/MS activity combining all frequency domains $\left(1-10^{5} \mathrm{~Hz}\right.$ ) in steep, fractured bedrock permafrost at the Matterhorn Hörnligrat field site (Figure 1). We analyze the AE/MS response of the failure event on 14 August 2015, which was identified as irreversible fracture displacement and by the collapse of the instrumented rock (Figure 11 in Weber et al., 2017). Then, we set out to explore the characteristics of propagating waves in detail through controlled experiments with artificial point sources simulating propagation of signals from the surface. Further, we quantify the filter effect (attenuation/amplification in relation to frequency) of the rock mass and analyze seasonal variations in microseismic activity. Using the derived filter band, we analyze and test the MS response of the earlier fail- 
ure event and of two further fracture events recorded by fracture displacement. Finally, we apply the same filter to a 2-year continuous data set and analyze the implication of seasonal-scale environmental forcing on event detection.

\section{Field Site and Methods}

\subsection{Site Description and Investigation History}

The Matterhorn is one of the most famous mountains in the European Alps at the Swiss-Italian border and has been an attractive destination for mountaineers since the first ascent in 1865. Mid of July 2003, a rock volume of approximately $1,500 \mathrm{~m}^{3}$ released from the Hörnligrat (northeast ridge of Matterhorn) at 3,500 $\mathrm{m}$ asl (above sea level) uncovering ice in the failure plane (Hasler et al., 2012). Motivated by this observation, this site has been instrumented with temperature sensors, crackmeters, and other geotechnical devices within and around the 2003 detachment zone located on the ridge since October 2007 (Hasler et al., 2008) with a further extension in June 2010 (Hasler et al., 2012). The mean annual air temperature is $-3.7^{\circ} \mathrm{C}$ (period 2011-2012) and precipitation mostly falls as snow with occasional infrequent rainfall events in summer (Weber et al., 2017).

Geologically, the Hörnligrat field site is located above the Penninic Metasediments and Ophiolites (Combin Zone) and consists of gneiss and amphibolite of the Dent Blanche nappe, which forms the main part of the Matterhorn summit (Pleuger et al., 2007). The Albite-Gneiss with a characteristic decimeter- to meter-scale mylonite banding dips SE parallel to the Dent-Blanche overthrust (Bucher et al., 2004). The light bands are compositionally lukocratic granitic gneisses and the darker, greenish bands comprise of Epidote-Chlorite-Aktinolithe-Albite-Gneiss. The principal schistosity/cleavage is developed parallel to the banding (Bucher et al., 2004). The area around the field site is strongly fractured but with a relatively stable surface at the north facing part of the ridge, indicated by the occurrence of lichens (Hasler et al., 2012). Laboratory investigations of rock samples from the field site exhibit (i) very low porosity ( $0.9 \%$ for gneiss and $1.3 \%$ for amphibolite, measured with a pycnometer), (ii) metamorphic lamination for gneiss and mixed fabric directions for amphibolite, and (iii) considerable increase of $P$ wave velocity with freezing ( $9 \%-13 \%$ for gneiss and $16 \%-20 \%$ for amphibolite) depending on the direction (perpendicular or parallel) of cleavage (Draebing \& Krautblatter, 2012). The east facing study area is located in the detachment zone of the 2003 rockfall event close to the Hörnligrat. The main fractures in this area have an extent of 3-40 m, exhibit a spacing of 0.2-2 $\mathrm{m}$ with apertures of 3-30 $\mathrm{m}$ and are oriented parallel to the ridge with a nearly vertical dip (fracture family A, Figure $2 \mathrm{~b}$ in Hasler et al., 2012). The surface in the detachment zone consists mainly of inferior surface-parallel fractures and free surfaces in proximity to the rockfall zone (Hasler et al., 2012).

Extensive permafrost with a thin active layer of a few meters (indicated by moderately positive temperature values at 1-m depth in summer) is expected on the north side of the ridge, while local permafrost with a considerable active layer of several meters (indicated by maximal rock temperature at 1-m depth up to $10^{\circ} \mathrm{C}$ ) is expected on the south side of the ridge (Hasler et al., 2012; Weber et al., 2017). The active layer thickness at the PERMOS Matterhorn borehole close to the Hörnlihut, located $200 \mathrm{~m}$ lower $\left(500 \mathrm{~m}\right.$ in $70^{\circ} \mathrm{N}$ direction on 3,295 $\mathrm{m}$ asl), is less than $4 \mathrm{~m}$ (PERMOS, 2016).

The Matterhorn Hörnligrat field site is affected by two main anthropogenic activities. First, the popular main climbing route traverses right through the field site. Several hundreds to few thousands of mountaineers climb the Matterhorn via the Hörnligrat every year. Most climbing activity is observed between 4 a.m. and 6 a.m. (UTC + 2:00) for the ascent, with descents spread out more over the course of the day. Little climbing activity is observed in the evening ( 8 p.m. until midnight, UTC + 2:00) with hardly any at night (midnight until 4 a.m., UTC + 2:00). Further, helicopter sight-seeing flights with tourists circumnavigate the Matterhorn several times a day, resulting in a very distinct but equally time limited signal.

\subsection{Instrumentation}

Beside the broadband AE/MS instrumentations (which is described further below), fracture displacement (perpendicular to and along fractures, recorded at 2-min intervals with an accuracy of $\pm 0.01 \mathrm{~mm}$ ) as well as rock temperatures at different depths $\left(5,10,20,30,50\right.$, and $100 \mathrm{~cm}$ at 2-min intervals with an accuracy of $\pm 0.2^{\circ} \mathrm{C}$ ) were recorded from summer 2015 until the beginning of 2018 (see Figure 1; for details on installation, see Weber et al., 2017). A time lapse camera took several (season dependent, but at least four) high-resolution images per day (12.0 MP, giving an approximate pixel resolution of $1.5 \mathrm{~cm}$ ) serving for visual inspection of the instrumentation and providing information on visible changes at the surface and mass loss. 
The AE/MS instrumentation required to cover the broadband frequency range of $1-10^{5} \mathrm{~Hz}$ consisted of three different transducer types and data acquisition systems. They were all colocated in the detachment zone within a distance of 1-2 m with the exception of a second seismometer located on the ridge about $20 \mathrm{~m}$ above (see Figure 1).

The high-frequency AE signal was measured with two piezoelectric sensors (Mistras Physical Acoustics Corporation $R .45,5-30 \mathrm{kHz}, 20-\mathrm{kHz}$ resonance frequency and $R 6 \alpha, 35-100 \mathrm{kHz}, 55-\mathrm{kHz}$ resonance frequency) using a custom-built acoustic emission monitoring system, the AE node (Girard et al., 2012). These two sensors were glued into the bottom of individual $20-\mathrm{cm}$-deep boreholes located in close proximity ( $\sim \mathrm{cm}$ apart). The low-power AE node triggers the signal analysis by the crossing of a threshold defining the beginning of an event. The recording ends when the threshold has not been exceeded for a post-trigger period of $400 \mu \mathrm{s}$ (Girard et al., 2012) with subsequent transmission of the detected hit using a wireless sensor network (WSN) in near-real time to a data collection server (Beutel et al., 2009). To reduce power consumption, the ultralow-power WSN lacks facilities for exact global time synchronization. Therefore, these data can only be timed with a 1-s accuracy with respect to global UTC reference time, although the relative timing accuracy between the two sensing channels within the AE node system is on the order of milliseconds.

The middle-frequency microseismic data were measured continuously using an accelerometer based on a Wilcoxon $728 \mathrm{~A} / \mathrm{T}(10-10,000 \mathrm{~Hz}, 24-\mathrm{kHz}$ resonance frequency), netADC data acquisition system and netSP+ seismological processor of the Institute of Mine Seismology with a sampling rate of $24 \mathrm{ksps}$ (kilo samples per second) from beginning until 19 August 2015 and a reduced sampling rate of 12 ksps since 20 August 2015 . According to the Nyquist-Shannon sampling theorem, frequencies up to $12,000 \mathrm{~Hz}$, respectively, $6,000 \mathrm{~Hz}$ can be detected. Data are synchronized to a global time reference using GPS $(<1 \mu \mathrm{s})$.

The low-frequency seismic data were measured using a Lennartz electronic low-noise seismometer LE-3Dlite MKIII $(1-100 \mathrm{~Hz})$ and Nanometrics Centaur digital recorder, a 24-bit high-resolution seismic data acquisition system disciplined by GPS $(<100 \mu \mathrm{s})$ with a sampling rate of 1,000 sps. The data acquired from all three systems recorded approximately $7 \mathrm{~GB}$ binary raw data per day that were transmitted to the Internet using directional WLAN (802.11a at $5 \mathrm{GHz}$ ).

However, these sensors with individual data acquisition systems provide variable sensitivities and differ in their mounting. The sensors for the high- and middle-frequency range were installed in boreholes (at $0.2 \mathrm{~m}$, respectively, at $1.1 \mathrm{~m}$ ), while the seismometers for the low-frequency range were mounted on the surface. For the high-frequency range, only the events crossing a fixed threshold of $50 \mathrm{~dB}$ ( $1.6 \mathrm{mV}$ without gain) were recorded, stored, and parameterized. Waveforms in the middle- and low-frequency range were monitored continuously, while the events were detected automatically with an adaptive trigger in post processing. Running these systems all year round requires an extensive amount of power of about $24 \mathrm{~W}$, which is mostly used for sensor signal amplification and wireless data transmission (especially by the accelerometer DAQ with an average power consumption $>15 \mathrm{~W}$ ). Therefore, the accelerometer DAQ has to be turned off during some periods in winter and during bad weather periods with heavy snowfall despite a large photovoltaic power supply $(4 \times 125$-Ah batteries with $3 \times 90$-W solar panels).

\subsection{Artificial Forcing Experiment Using Point Sources}

To characterize the field site and to investigate its AE/MS response, two reproducible experiments with artificial point sources were performed: (1) An artificial rebound hammer experiment and (2) a rock drop experiment.

In the first experiment, nine impulses were generated at each of the four different locations (indicated with yellow stars in Figure 1) on 26 July 2016 in the course of the morning. The impulses were generated by a Proceg Original Schmidt rebound hammer, a portable instrument for nondestructive compressive strength and homogeneity assessment with a standard impact energy $E=2.207 \mathrm{Nm}$ (p.3 ; Proceq, 2017). The rebound hammer was chosen as a point source, because it generates a calibrated signal with consistent energy in the complete frequency domain under observation and thus allows investigations on frequency-dependent attenuation.

In the second experiment, small debris fall events were artificially generated by dropping a piece of rock $(\sim 3 \mathrm{~kg}) 10$ times next to the seismometer $\mathrm{SM}_{\text {scarp }}$ and 7 times next to the seismometer $\mathrm{SM}_{\text {ridge }}$ from $\sim 0.75-\mathrm{m}$ 
height. The order of magnitude of the impulse energy $E$ was estimated as follows:

$$
\begin{gathered}
E=m_{\text {rock }} \cdot g \cdot H_{\text {drop }} \\
E=3 \pm 0.5 \mathrm{~kg} \cdot 9.81 \mathrm{~m} / \mathrm{s}^{2} \cdot 0.75 \pm 0.1 \mathrm{~m} \\
\approx 22.5 \pm 6.75 \mathrm{Nm}
\end{gathered}
$$

The response of dropping rocks is of interest, because it simulates the impact of small rockfalls reflected in the waveform as well as in the frequency domain.

\subsection{Field Data: Processing and Analysis}

\subsubsection{Data Processing and Event Triggering}

The three data acquisition systems provided different data types. The AE node triggers on and parameterizes hits using a constant, empirically defined threshold of $50 \mathrm{~dB}$ ( $1.6 \mathrm{mV}$ without gain) constituting a compromise between trigger sensitivity and noise level. The two acquisition systems for the accelerometer and seismometers record the full signal waveform on all three components (vertical, north, and east) continuously. After removing the instrument response, the waveforms are representative of the ground motion velocity in $\mathrm{m} / \mathrm{s}$. Events are triggered using a recursive short-term/long-term average (STA/LTA) algorithm (Krischer et al., 2015; ObsPy, 2017; Withers et al., 1998). The peak amplitude $(A)$ of the ground velocity envelope (Dammeier et al., $2011)$ and the energy $(E)$ are quantified for all trigger records. The energy was calculated by discrete summation of the signal's square amplitude for the duration of the event (Evans, 1979). The sensitivity of event triggering with STA/LTA depends on the temporally changing long-term average. Following the approach of Walter et al. (2008), the relative signal strength of the events detected, given by the peak amplitude of each event, is used to investigate and clean the temporally changing trigger sensitivity by selecting a set of events above a defined threshold.

\subsubsection{Cross Correlation}

Cross correlation is a measure of similarity of two time series. Cross correlation has been used in seismology to identify repeating earthquakes (e.g., Gibbons \& Ringdal, 2006; Holland, 2013). In this study, the normalized cross correlation CC based on the Pearson correlation (p. 292 ; LeBlanc, 2004) was applied for searching for a feature $A$ (short reference signal) in a longer signal $B$ record

$$
\mathrm{CC}=\frac{\sum\left(A-\mu_{A}\right) \cdot\left(B^{\prime}-\mu_{B^{\prime}}\right)-1}{\operatorname{LENGTH}(A) \cdot \sigma_{B^{\prime}} \cdot \sigma_{A}}
$$

where $B^{\prime}$ is the sliding subset of $B$ with the same length as $A, \mu$ the mean, and $\sigma$ the standard deviation of the corresponding features.

\subsubsection{Filter Effect Estimation}

The filter effect $k$ of the rock was estimated by the deconvolution of the waveform of two artificially generated, identical point sources $/$ and $m$ at different locations

$$
\begin{gathered}
I=k * m \\
k=I * m^{-1}
\end{gathered}
$$

This approach is based on the principle of seismic reciprocity, an interchange of point sources and receivers (Knopoff \& Gangi, 1959). The two point sources / and $m$ are on a virtual line with the receiver where $m$ is closer to the receiver. Channel $k$ in the signal frequency domain was described as

$$
\hat{k}=\frac{\hat{l}}{\hat{m}}
$$

where $\hat{x}$ indicated the fast Fourier transformation (FFT) of the seismogram $x$. 


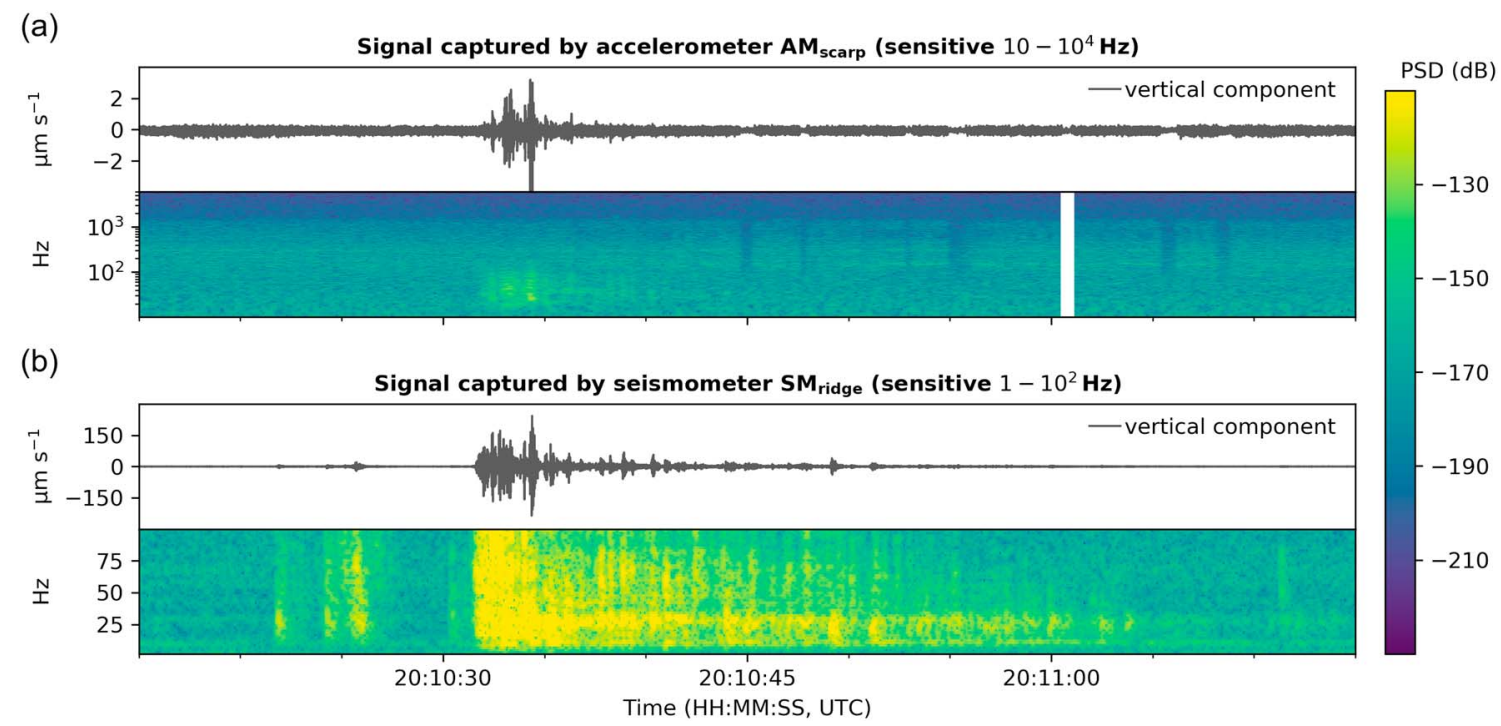

Figure 3. Waveforms in velocity and power spectral densities, in decibel, of the vertical component over the period of the rockfall event on 14 August 2015

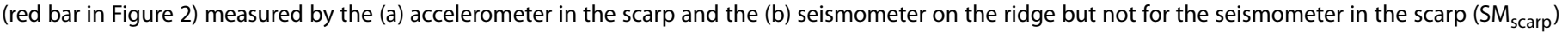
because of a system failure. Even though the microseismic data enabled a more precise timing, the distinction between fractures and possible rockfall impacts is not trivial.

\section{Results and Interpretation}

First, this section presents the AE/MS response and corresponding fracture displacement data of the rockfall on 14 August 2015 and the two preceding fracture events. Then, results from two controlled experiments are presented and discussed with respect to the representativeness of natural occurring fracture/failure events. Based on this analysis, we further investigate the applicability to longer-term time series in the following section.

\subsection{Rockfall on 14 August 2015 With Preceding Fracture Events}

A rockfall event with a volume of 2 to $3 \mathrm{~m}^{3}$ was recorded by a crackmeter and AE/MS measurements on 14 August 2015 UTC 20:10 (red bar in Figure 2). The MS response to the failure measured at the accelerometer (AM) and the seismometer on the ridge $\left(\mathrm{SM}_{\text {ridge }}\right)$ is shown in Figure 3. A preceding fracture displacement of $13.2 \mathrm{~mm}$ was recorded $10 \mathrm{hr}$ previously and a much smaller displacement of only $0.15 \mathrm{~mm}$ was observed a few days earlier on 9 August 2015 (gray bars in Figure 2a). Most of the threshold-triggered AE hits were captured just before or at these previous fracture displacements, but none during the failure event itself (Figures $2 b$ and $2 \mathrm{c}$ ). In contrast, the waveforms measured at the accelerometer and seismometers show high amplitude values on several occasions, which are asynchronous of the measured fracture displacement (Figures $2 d-2 f$ ). However, there are amplitude peaks in the MS range coincident with the failure and the two preceding displacements, but with lower amplitudes. These waveform records show that the colocated accelerometer and seismometer capture a few common events but also many independent ones (not detected simultaneously by different sensors, Figures $2 \mathrm{~d}$ and $2 \mathrm{e}$ ). A similar behavior can be observed for the two identical seismometers with different locations (Figures $2 \mathrm{e}$ and $2 \mathrm{f}$ ). This behavior indicates an influence of both the signal frequency and the propagation path on the waveforms recorded at the receiver. To investigate these effects, we performed an artificial rebound hammer experiment.

\subsection{Artificial Rebound Hammer Experiment}

Figure 4 gives an overview of the results of the rebound hammer experiment, in which we applied nine active rebound hammer impulses representing a point source at Locations 1-4 (see section 2.3). We only show a representative period of $30 \mathrm{~s}$ containing two rebound hammer impulses, but the full record containing all nine rebound hammer impulses was consistent and used for analysis. The AE hits triggered at the two acoustic sensors (high and low frequency) are indicated with cyan diamonds. The waveform and its spectrogram are shown for the continuously measured microseismic signal at the accelerometer and at the two seismometers for all three components ( $\mathrm{Z}=$ vertical, $\mathrm{N}=$ north, and $\mathrm{E}=$ east). All events detected with the recursive STA/LTA algorithm using $0.5 \mathrm{~s}$ and $10 \mathrm{~s}$ for the short-term and long-term average, are indicated with cyan diamonds. 
This first result showed that the rebound hammer impulse contained energy in the frequency range from $\mathrm{Hz}$ to $\mathrm{kHz}$ with a specific distribution. The detection of the artificial point source depends on the sensor's frequency sensitivity and the distance between point source and sensor (see Figure 5). As expected, a strong decrease in the signal amplitude and band spectrum of the accelerometer $\left(\mathrm{AM}_{\mathrm{scarp}}, 10-6,000 \mathrm{~Hz}\right)$ is visible with distance from Locations 3 and 2 (see white ellipses in Figure 4). While the spectrogram for Location 3 indicates substantial energy in the whole frequency range, only little energy in the lower-frequency band can be seen in the spectrogram for Location 2. This observation is consistent with the theoretical frequency-dependent attenuation due to internal friction [see equation (1)].

Figure 6 shows a channel by channel cross correlation between a reference signal and the signals measured at all sensors. The reference signal (Figure 6a) was the first rebound hammer point source generated at Location 3 (red bar in Figure $6 \mathrm{~b}$ ) and measured at the closest seismometer in the scarp. The cross correlation between the reference signal and the signals detected at the seismometer in the scarp (of the successive impulse experiments) show a very high similarity (>0.9) for all three components (see Figure $6 \mathrm{~b}$, middle) and all eight successive artificial point sources generated at Location 3 . The similarity strongly decreases with increasing distance between the point source and the seismometer (Location 2: $1.7 \mathrm{~m}$; Location 4: 4.8 m) until it is not distinguishable from noise any more (Location 1:8.2 m). The similarity between the reference signal and the seismometer on the ridge as well as the accelerometer in the detachment is weak or not detectable. Consequently, the waveform generated by the point source must have changed substantially during its travel through rock and therefore can hardly be compared directly, unless the locations of the point source and of the detection are very close. This observation demonstrated the strong influence of the propagation path on the waveforms recorded at the receiver.

The rebound hammer experiments were used to estimate the filter effect $k$ of the rock [following equations (7) and (8)] between Locations 3 and 4, as these point sources are located on a line with the seismometer. The mean filter spectrum ratio of these artificial point sources is shown in Figure 7a for each component individually as well as combined (ALL). Energy loss in higher frequencies was expected due to attenuation in the heterogeneous material (see section 1.2). Surprisingly, an amplification (ratio factor $>1$ ) was observed in the intermediate frequency band. Figure $7 \mathrm{~b}$ shows the sum of the ratio factors of all components combined (Figure 7a) for different frequency windows (size and center). This results in a frequency window with the most intense amplification ranging from 33 to $67 \mathrm{~Hz}$. The reason for this signal amplification is not clear. This amplification might be attributed to energy transformation or concentration in some frequency bands as an additional energy source can be excluded. The other plausible explanation could lie in a possible phenomenon of acoustic resonance, which describes an amplification in a medium when the wave frequency exactly matches integer multiples of the medium's fundamental frequency. The site or topographic effects in rock slopes (Ashford et al., 1997; Moore et al., 2011) and related earthquake-induced slope failures (Del Gaudio et al., 2014; Kleinbrod et al., 2017; Moore et al., 2012) have shown site-specific amplification suggesting a resonance effect at the fundamental frequency (ranging from a few $\mathrm{Hz}$ to tens of $\mathrm{Hz}$ depending on the scale and site characteristics). The damping in the upper frequency corresponded to the theoretical frequency-dependent attenuation caused by internal friction [see equation (1)]. But there currently is no clear explanation for such filtering out of low frequencies.

When applying a band-pass filter in the frequency band $33-67 \mathrm{~Hz}$, the detection of the rebound hammer point source events (magenta diamonds in Figure 4) has been improved in comparison to the unfiltered case (cyan diamonds in Figure 4). The effect of this filter is visualized in more detail in the supporting information in Figure S2 (band-pass filtered, respectively, band-stop filtered seismogram and spectrogram). Table 1 gives a summary of the number of triggered events out of the nine artificial rebound hammer impulses with and without filtering. This underpins again the importance of appropriate filtering for event detection. However, a few events are still not detected after filtering (in particular, at Location 2), probably due to a high noise level leading to an enhanced long-term signal average of the STA/LTA trigger algorithm.

\subsection{Artificial Debris Fall Experiment}

A second experiment with artificial point sources was performed. Here small debris fall events were simulated by dropping a piece of rock (see section 2.3) at two different locations, once next to the seismometer in the scarp (10 point sources, left part Figure 8 ) and once next to the seismometer on the ridge (seven point sources, right part Figure 8). 

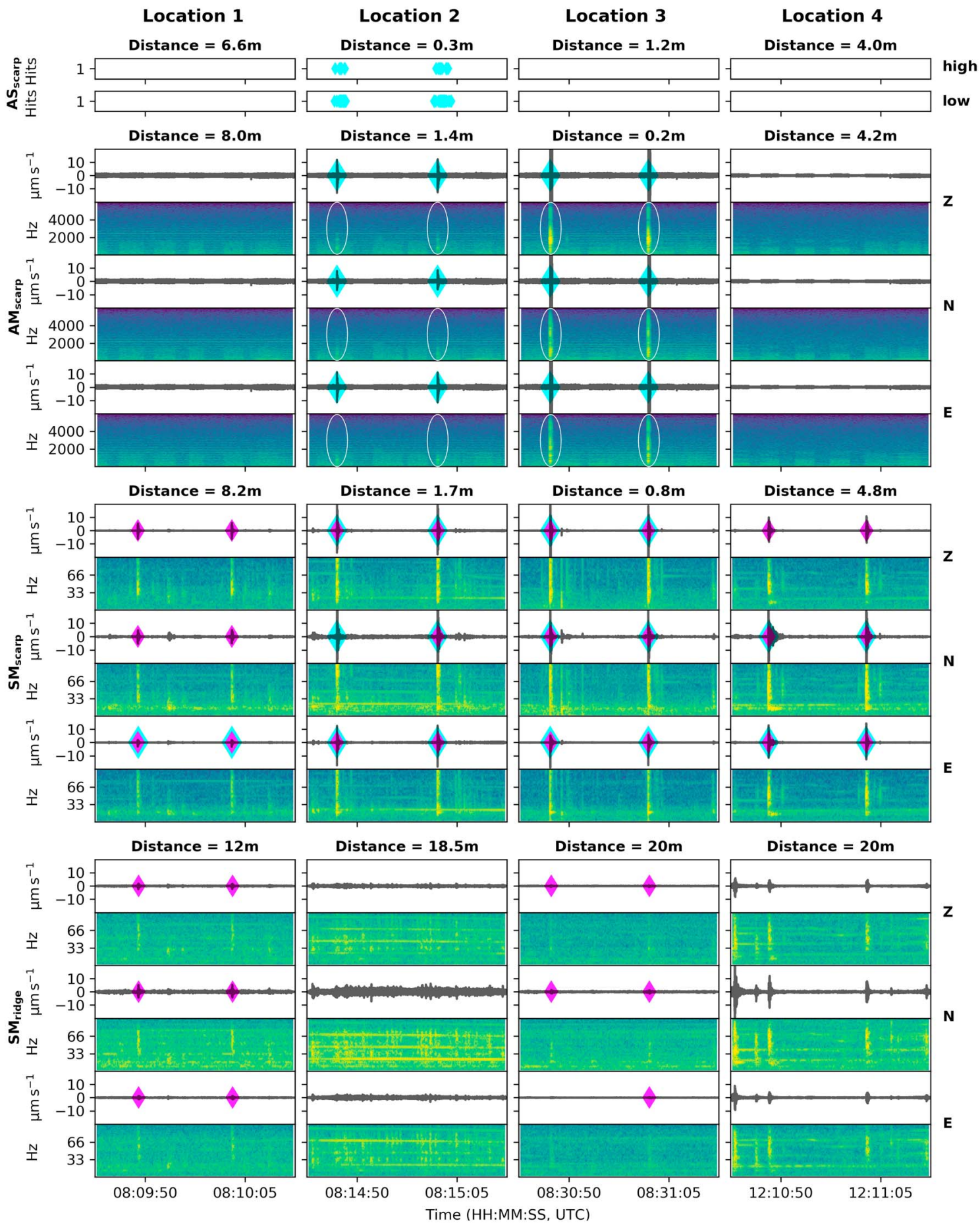

Figure 4. Experiment applying nine active rebound hammer impulses as a point source at Locations $1-4$. A period of $30 \mathrm{~s}$ of the traces and their spectrograms for all three components $(\mathrm{Z}=$ vertical, $\mathrm{N}=$ north, and $\mathrm{E}=$ east $)$ are shown for all locations. This period only contains two of nine impulses as the full record is consistent. The approximated distance between point source and sensor is given in meters above each plot (see Figure 1). AE hits triggered by the two AS (acoustic sensors, high and low frequency) are indicated with cyan diamonds. The microseismic signal is recorded continuously with an accelerometer (AM) in the scarp and two seismometers (SM), one in the scarp and another on the ridge. Events were detected by a short-term/long-term average algorithm with 0.5- and 10-s averages for the seismometers and 0.05- and 10-s averages for the accelerometer. Cyan diamonds indicate triggered events without filtering, while magenta diamonds indicate triggered events for the seismometers in the filtered frequency range of $33-67 \mathrm{~Hz}$. The logarithmic power spectral density from blue to yellow indicates increasing values (same scale as in Figure 3). 


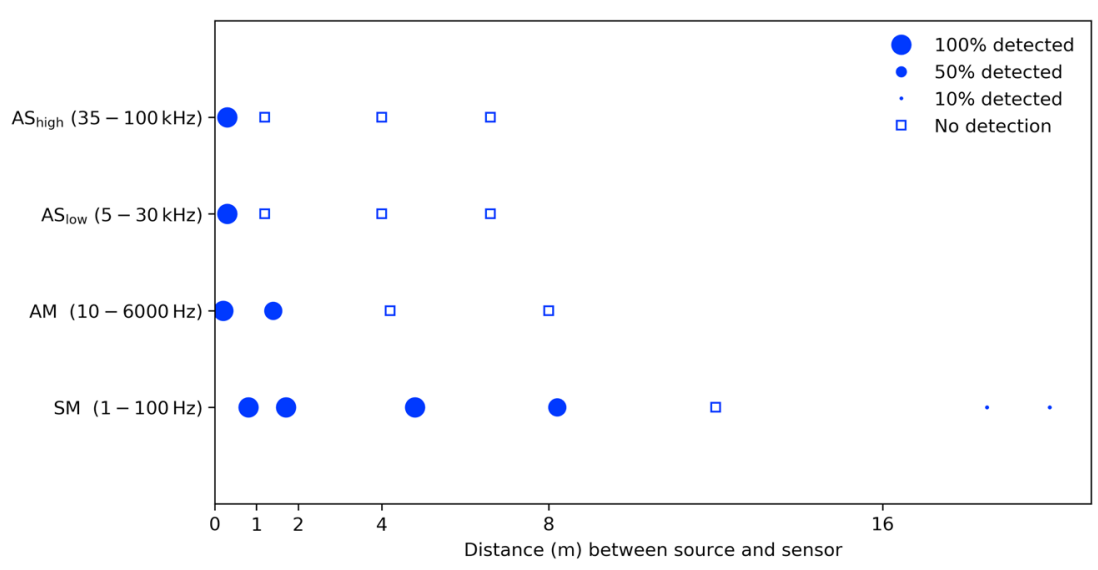

Figure 5. Frequency-dependent (sensor types bandwith) detection range using active rebound hammer point sources at Locations 1-4 (26 July 2016). The size of the circles indicate the detection rate of the nine artificial rebound hammer impulses applying a fix threshold ( $50 \mathrm{~dB}$ with gain equal to $1.6 \mathrm{mV}$ without amplifier) trigger for the acoustic sensors (AS) and a short-term/long-term average algorithm for the accelerometer (AM) and the seismometers (SM). The squares indicate undetected impulses.

The filtering shows no improvement if the point source is located close to the seismometer (Figures $8 \mathrm{c}$ and $8 \mathrm{f}$ ). The explanation lies in the short traveling path of the signals and the resulting attenuation, derived from geometric spreading, internal friction, and scattering, is negligible. With an increased distance $(\sim 20 \mathrm{~m})$ between source and seismometer, the filtering has strongly improved the detection of the point sources (Figures $8 \mathrm{~d}$ and $8 \mathrm{e}$ ). While none of the $10 \mathrm{impulses}$ have been detected at the seismometer on the ridge without the filter, all 10 impulses have been detected after filtering on the vertical component $(Z)$ and eight impulses have been detected on the north $(\mathrm{N})$ and east $(\mathrm{E})$ components (Figure 8e). For the seismometer in the scarp, without filtering five impulses were already detected on the east (E) component but none on the vertical $(Z)$ and north (N) components, whereas all impulses have been detected on all three components after filtering (Figure 8d).

\subsection{Representativeness of Artificial Sources for Fracture/Failure Events}

The experiments using artificial point sources described, for example, rebound hammer and dropping rocks, were aiming to characterize the propagation of AE/MS signals. Even though the waveform might not be representative of natural fracture and failure events, cross correlation analysis shows a strong change of waveform with propagation (Figure 6). Therefore, a signal representing a similar energy-frequency distribution or covering at least the same frequency range is found to be more important than a specific waveform. A qualitative comparison shows that a rebound hammer impulse performs a similar signal in the frequency domain (Figure 4) as the signal emitted by the fracture/failure events (Figure 3). The second artificial forcing experiment (dropping rocks) not only simulates the impact of small rockfalls but also generates a signal with more energy compared to the rebound hammer and interestingly exhibits similar behavior in signal propagation.

\section{Application to Naturally Occurring Time Series}

Based on the findings of the artificial transmission experiments, we further investigate the transfer of the proposed filtering methods for natural events originating from irreversible fracture displacement and provide a sensitivity analysis using data collected during a 2-year period using the setup described earlier.

\subsection{Application to Natural Events Originating From Fracture Displacements}

The band-pass filtering derived from the two artificial experiments was applied to naturally occurring events. Crackmeter data provided useful information on the occurrence of fracture displacements between two consecutive measurement points and therefore is limited in timing to the resolution of the recording interval ( $2 \mathrm{~min}$ ). Although the microseismic data enabled a more precise timing, the distinction between fractures and potential rockfall impacts cannot be made. Figure 9 shows two additional examples of fracture displacements measured in a 2-min interval at crackmeter $\mathrm{CR}_{\text {old }}$ located in the scarp on 27 and 30 June 2015 (for location see Figure 1). While Figure 9a shows the 6-day time series of the crackmeter data, Figures 9b and 9c is a zoom-in of the observed fracture displacement events. Figures $9 \mathrm{~d}$ and $9 \mathrm{e}$ show clear microseismic events with the same characteristics during both displacement periods. After filtering, the sensitivity of the event detection was 
(a)
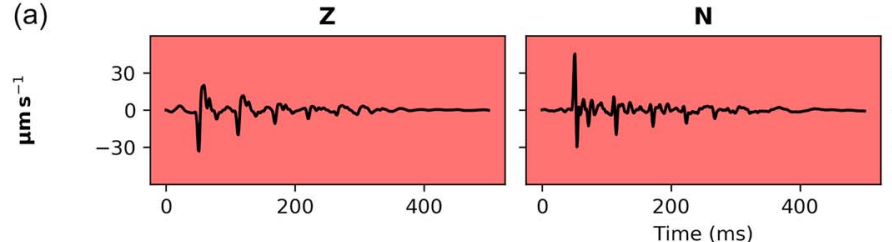

(b)
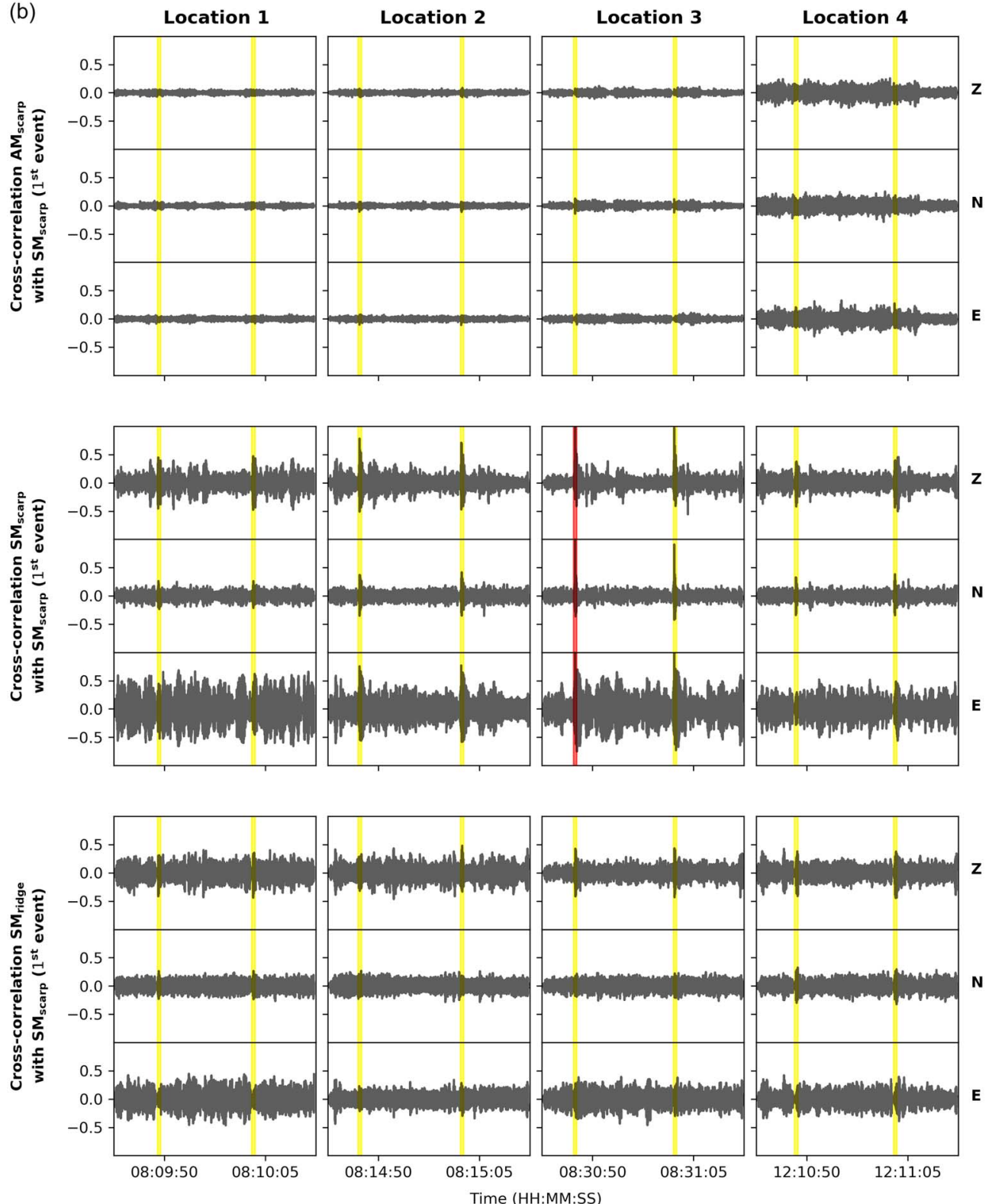

Figure 6. Channel by channel cross correlation between a reference event and the traces. (a) Reference impulse generated at Location 3 (marked with a red bar in b) and measured at the seismometer scarp, (b) temporally cross correlated with impulses (marked with yellow bars in b) generated at different locations.

strongly improved in three ways: First, the seismic noise, a combination of different signals (e.g., sourced by anthropogenic activity and/or environmental factors such as rainfall and wind) was reduced. Second, the fracture displacement was simultaneously detected in all components at both seismometers. Third, a few events only detected in the east direction in the scarp, probably false positives, were not detected anymore. Similar findings were made for the fracture and failure event described on 14 August 2015 (Figures 2 and S3). Thus, 
(a)

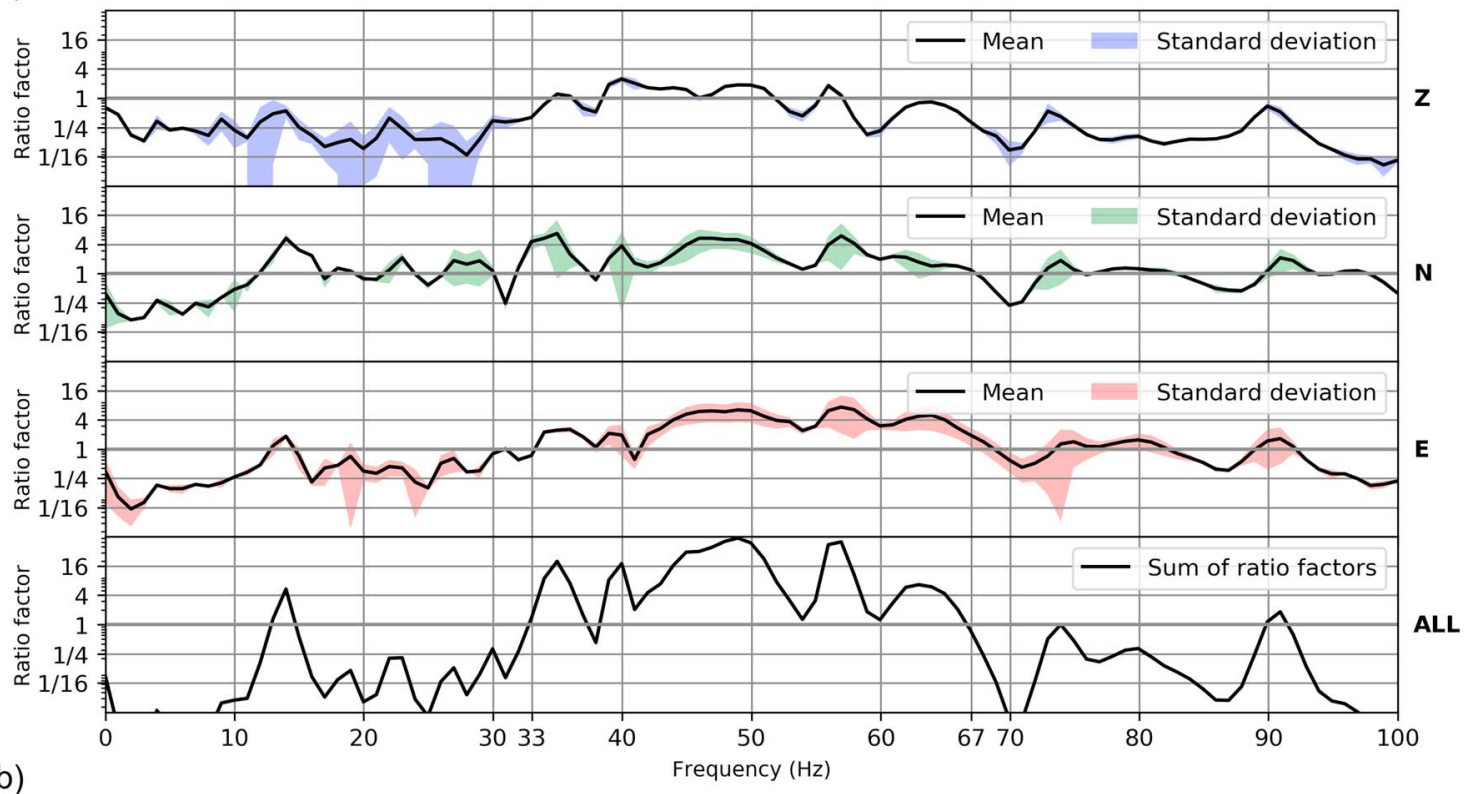

(b)

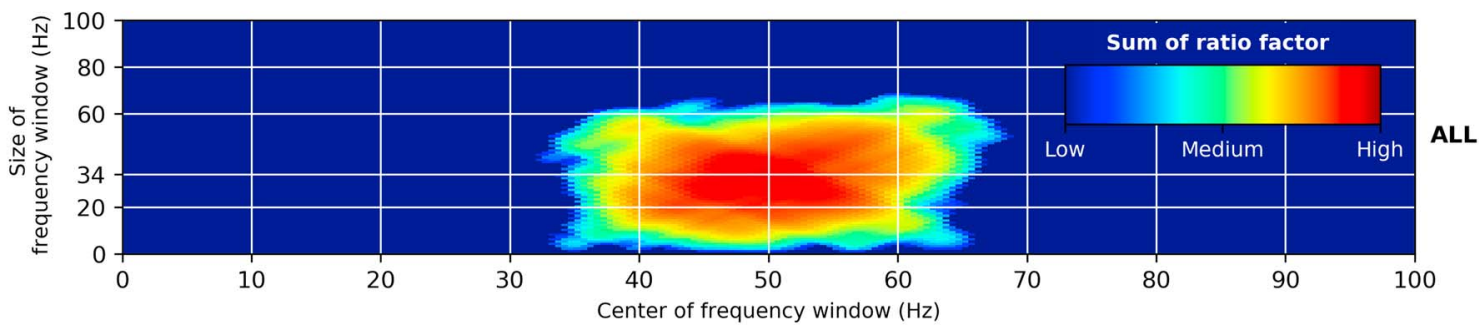

Figure 7. (a) Filter spectrum between Locations 3 and 4 indicating mean and standard deviation of 81 combinations. Amplification in the middle part of the frequency range. (b) Determining the frequency window with the highest amplification, where the boundary of the amplification window is given by the window center \pm 0.5 times window size, that is, $50 \pm 0.5 \cdot 34 \mathrm{~Hz}$ results in the frequency band $33-67 \mathrm{~Hz}$.

the application of the proposed filtering method was highly successful for observed fracture displacement events and confirms its transferability to natural displacement and fracture events.

\subsection{Analysis of 2-Year Continuous Time Series Data}

Microseismic activity was recorded almost continuously for two consecutive years, and events were detected automatically in postprocessing by applying a recursive STA/LTA algorithm using $0.5 \mathrm{~s}$ and $10 \mathrm{~s}$ for the short-term and long-term average. This automatic event detection algorithm was based on a ratio between two running averages. Thus, the event-triggering procedure was sensitive to variations in background seismicity, which complicates the analysis of event time series. Therefore, the weakest events detected, a proxy for trigger sensitivity with temporal variations, are used to set the lower peak amplitude level (i.e., $3 \cdot 10^{-6} \mathrm{~m} / \mathrm{s}$ without the filter and $5 \cdot 10^{-7} \mathrm{~m} / \mathrm{s}$ in the band $33-67 \mathrm{~Hz}$ for the seismometer in the scarp and $6 \cdot 10^{-6} \mathrm{~m} / \mathrm{s}$, respectively, $2 \cdot 10^{-6} \mathrm{~m} / \mathrm{s}$ for the seismometer on the ridge, see Figure $\mathrm{S} 4$ ). This enabled selection of the events which were strong enough to be triggered at any time (Walter et al., 2008). This reduced set of triggered

Table 1

Number of Automatically Triggered Events on the Individual Components ( $Z=$ vertical, $N=$ north and $E=$ east $)$ With and Without Filtering at Each Seismometer Out of the Nine Artificial Rebound Hammer Impulses Generated at Each of Locations 1-4

\begin{tabular}{lcccc}
\hline & Location 1 (Z, N, E) & Location 2 $(\mathrm{Z}, \mathrm{N}, \mathrm{E})$ & Location 3 (Z, N, E) & Location 4 (Z, N, E) \\
\hline $\mathrm{SM}_{\text {scarp }}$, without the filter & 008 & 579 & 999 & 099 \\
$\mathrm{SM}_{\text {scarp}}$, filtered 33-67 Hz & 999 & 869 & 999 & 999 \\
$\mathrm{SM}_{\text {ridge, }}$ without the filter & 000 & 000 & 000 & 014 \\
SM $_{\text {ridge, }}$ filtered 33-67 Hz & 888 & 313 & 451 & 666 \\
\hline
\end{tabular}



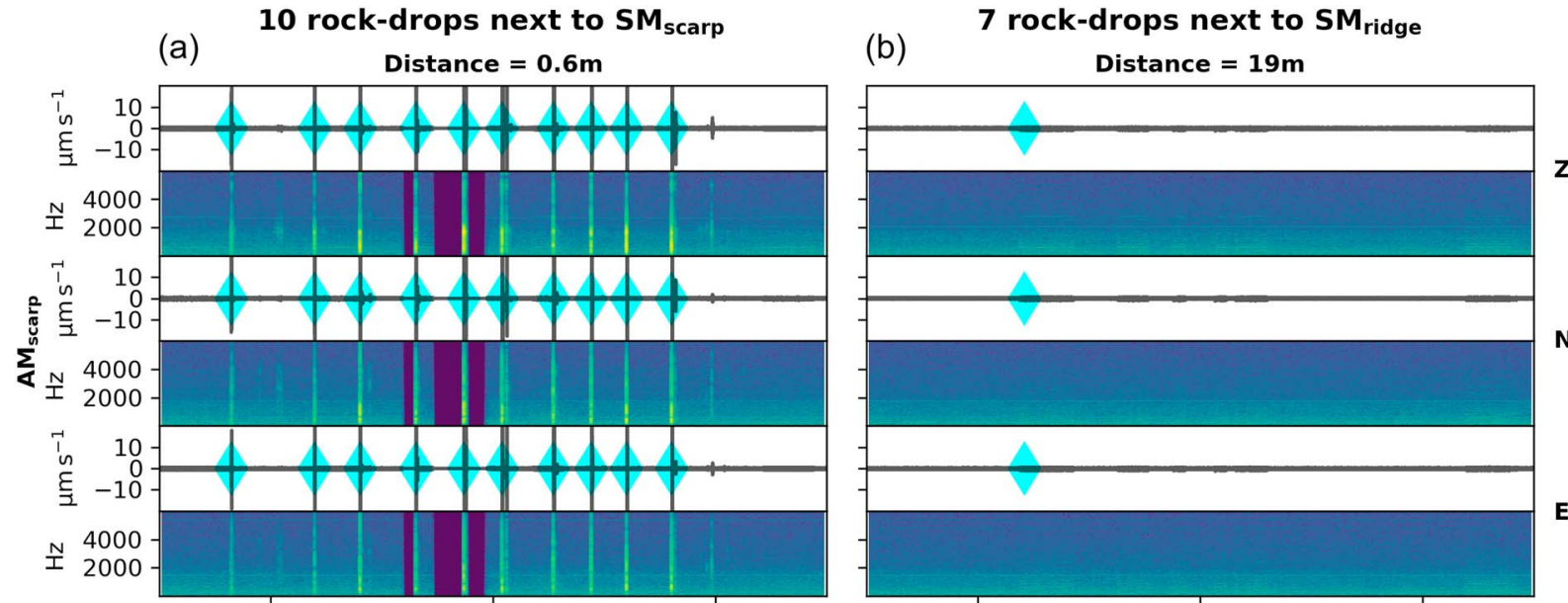

(c)

Distance $=0.4 \mathrm{~m}$

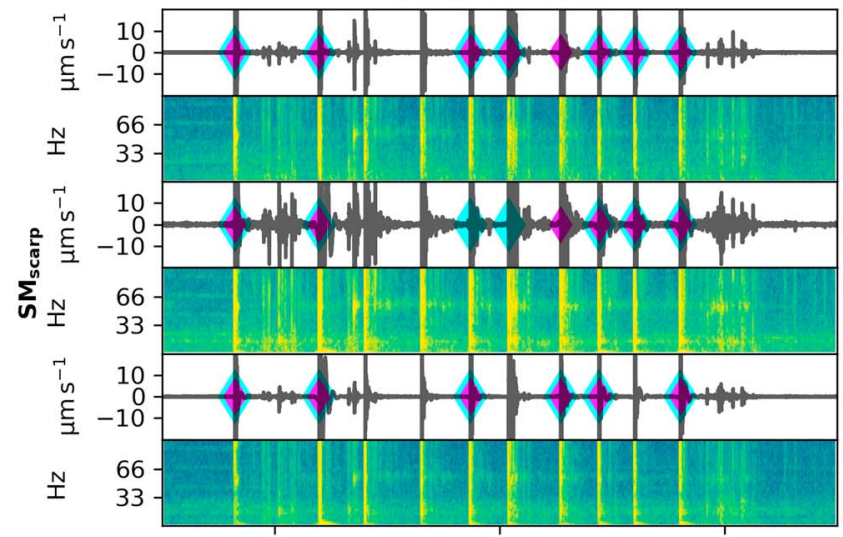

(d)

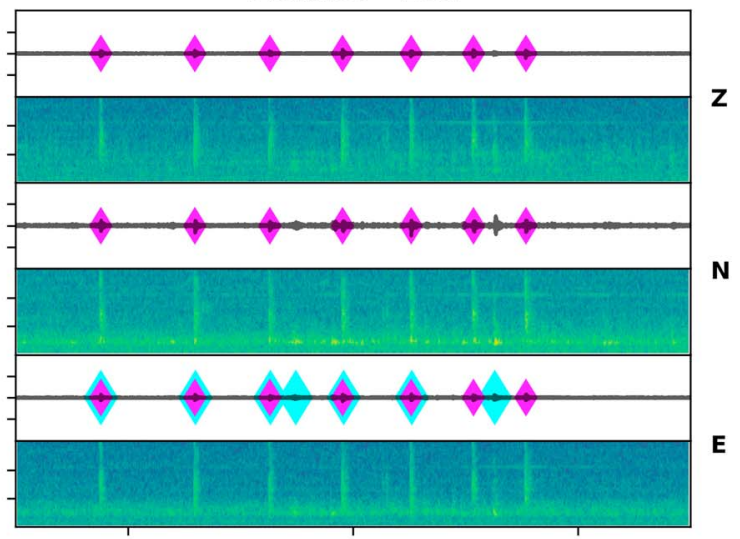

(e)

(f)
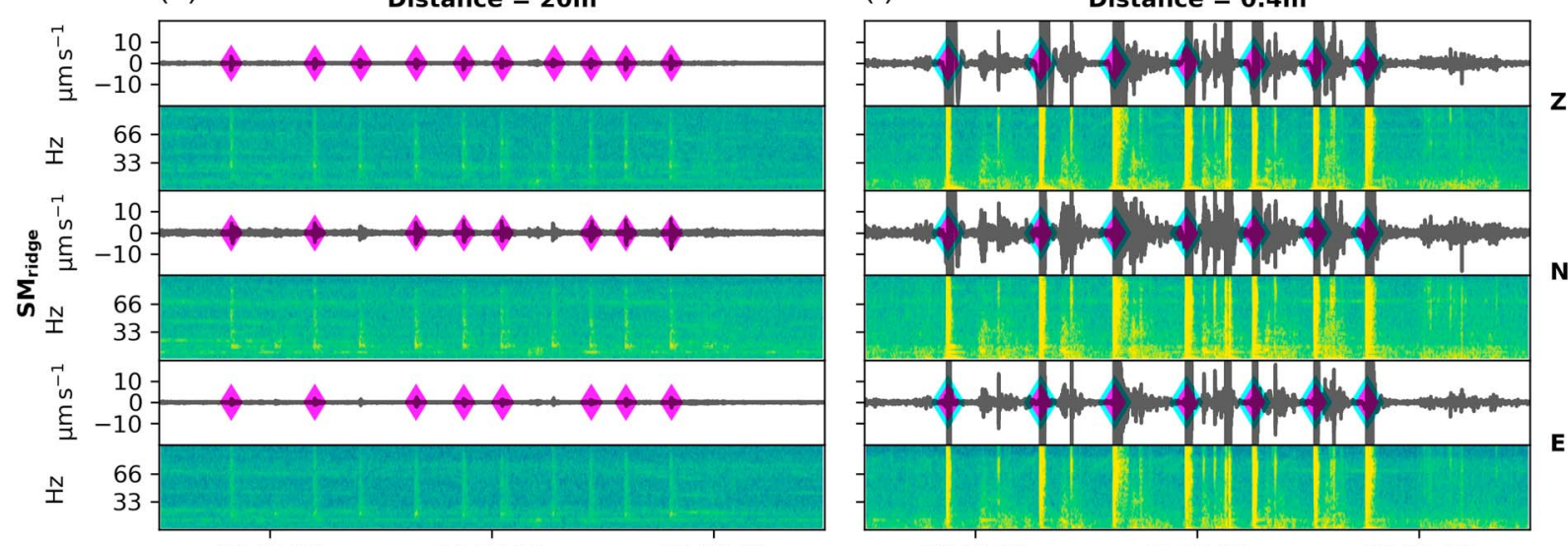

$12: 34: 00$

$12: 34: 30$

$12 \cdot 35: 00$

Time (HH:MM:SS)

Figure 8. Experiment with dropping rocks as artificial point source (27 July 2015) as a simulation for debris fall. The traces and spectrograms of the measured signal at both seismometers are shown for the 10 rock drops in the scarp $(a, c, e)$ and for the seven rock drops on the ridge $(b, d, f)$. The events were detected by a short-term/long-term average algorithm with 0.5 - and 10-s averages for the seismometers and 0-05- and 10-s averages for the accelerometer. The cyan diamonds mark detected events without filtering, while the magenta diamonds mark events detected at the seismometers after filtering. The logarithmic power spectral density from blue to yellow indicates increasing values (same scale as Figure 3). No acoustic events were detected. 
(a)
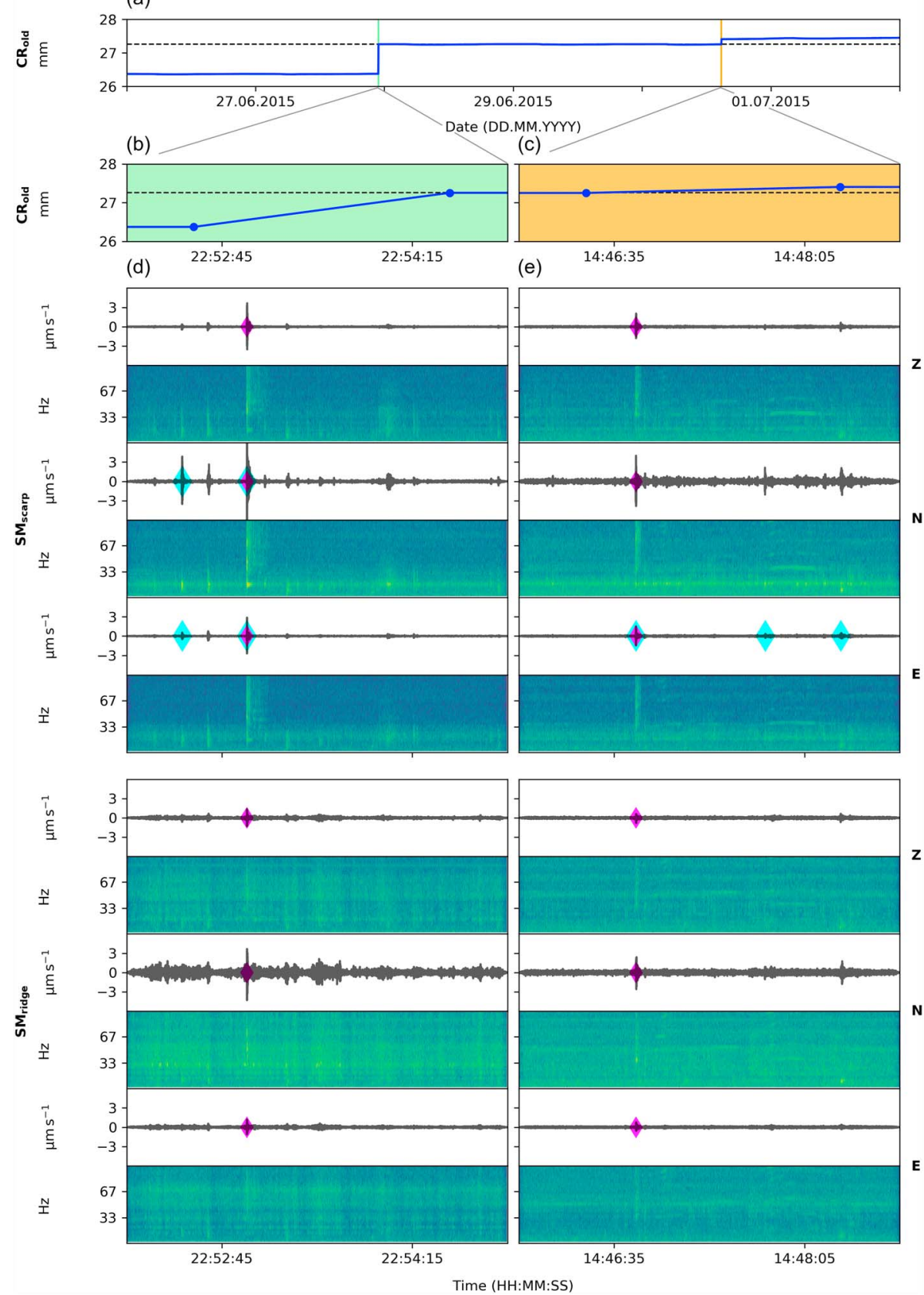

Figure 9. (a) Fracture displacement measured at crackmeter $\mathrm{CR}_{\text {old }}$ in summer 2015 with a zoom-in at the (b) green and (c) orange bar. (d, e) Seismic activity during irreversible fracture displacements [27 June (d) and 30 June (e) 2015] measured at both seismometers. The events were detected by a short-term/long-term average algorithm with 0.5 - and $10-s$ averages. Cyan diamonds indicate triggered events without filtering, while magenta diamonds indicate triggered events for the seismometers in the $33-67-\mathrm{Hz}$ range. The logarithmic power spectral density from blue to yellow indicates increasing values (same scale as in Figure 3). No acoustic events were detected and the accelerometer was not running yet. 
(a)

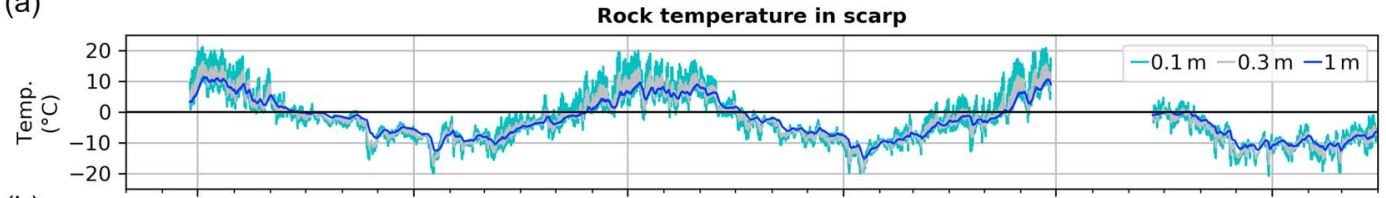

(b)

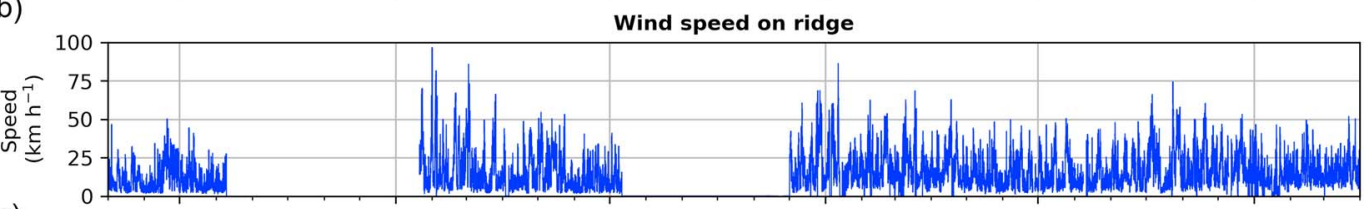

(c)
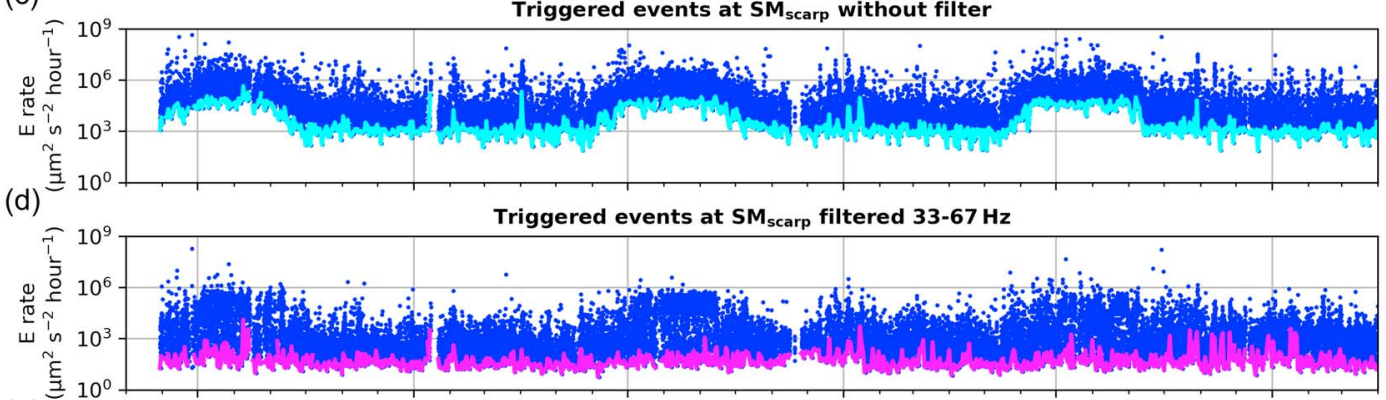

(e)

Triggered events at $\mathrm{SM}_{\text {scarp }}$ without filter during night (0-4 UTC+02:00)

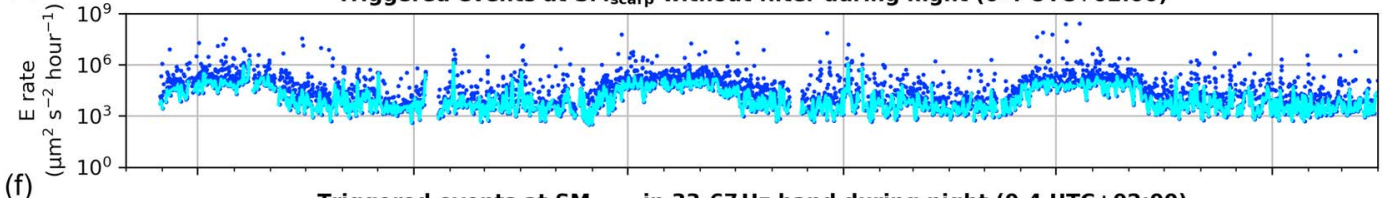

(f)

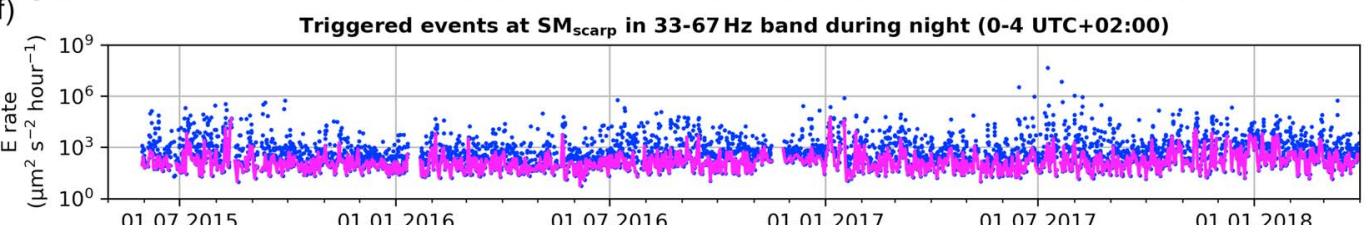

(g)

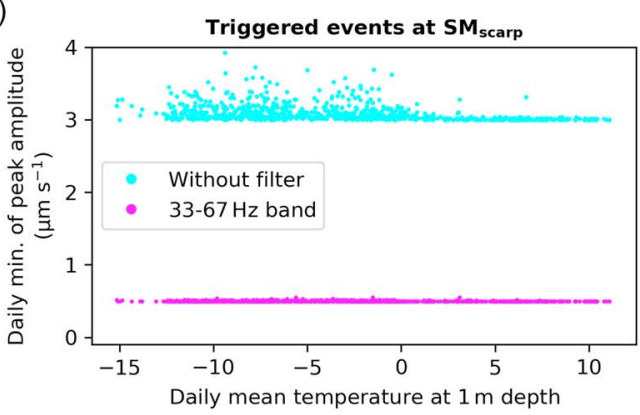

(h)

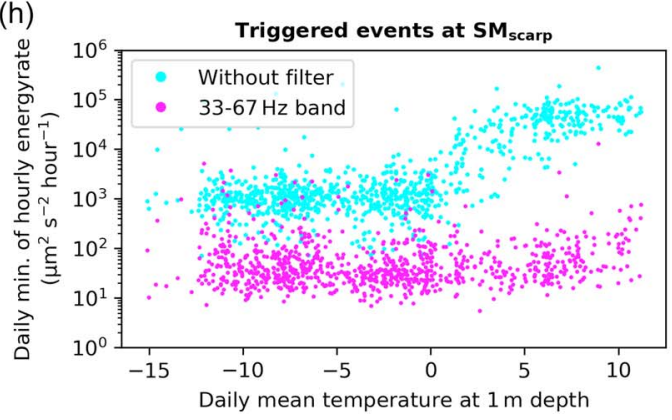

Figure 10. Two-year time series of (a) rock temperature at 0.1-, 0.3-, and 1-m depth in the scarp, (b) wind speed on the ridge, and ( $c-f)$ energy rate for the triggered seismic events in the scarp (blue points represent hourly energy rates, while cyan and magenta points indicate their daily minima). The temperature dependency of the (g) peak amplitude and (h) energy rate for the triggered seismic activity in the scarp.

events, used in Figures 10c-10f, is the combination of natural (including drivers of damage) and anthropogenic (e.g., mountaineers or helicopters) sources allowing time series analysis. Figure 10 shows a 2-year time series of rock temperature in the scarp at three different depths (Figure 10a), wind speed measured on the ridge (Figure 10b), and the energy rate for the microseismic events recorded at the seismometer $\mathrm{SM}_{\text {scarp }}$ without and with filtering (see Figures 10c and 10d). We further show in Figures 10e and 10f the data from nighttime only in order to exclude anthropogenic disturbance from mountaineering activity and helicopter flights during the day. During bad weather periods with strong wind, we would expect increased hourly energy rate for the events triggered (without and with filter), while accumulated snow could reduce this 
effect. However, we can see no clear pattern nor relationship between wind velocity, snow cover, and hourly energy rate.

Longer periods (summer) with positive temperature values (Figure 10a) seem to have an influence on the daily minimum energy rates $\left(E_{\text {rate }}\right)$ for the events triggered without the filter (Figure 10c), but almost no influence in the case of the events triggered in the filtered band $33-67 \mathrm{~Hz}$ (Figure 10d). This dependency is shown quantitatively in Figure $10 \mathrm{~h}$ for the events triggered without the filter (cyan) and with filter band $33-67 \mathrm{~Hz}$ (magenta). The energy rate of the events triggered without the filter (cyan) shows a strong increase with the onset of positive temperature values, while the energy rate of the events triggered in the filtered band (magenta) is almost constant over the whole temperature range. The daily minimum of the peak amplitude (Figure 10g) was temperature independent as the threshold for the peak amplitude was high enough to remove the trigger sensitivity. This bias with positive temperature values could not be caused by mountaineers, as it was also observed during the night (Figures 10e and 10f) with almost no or negligible human activity.

In contrast, the events triggered in the band $33-67 \mathrm{~Hz}$ have an almost constant baseline offset over the whole temperature range (Figure 10h). Such an unbiased set of events appears to be an important prerequisite for successful statistical analysis of seasonally varying environmental forcing. Further, it is essential to distinguish seismic activity generated by changes in the material from anthropogenic seismic activity.

\section{Discussion}

This study successfully captured AE/MS activity in steep, fractured bedrock permafrost in the frequency band of $1-10^{5} \mathrm{~Hz}$ simultaneously for the first time. This was achieved using three separate data acquisition systems and sensor types covering different frequency ranges but also providing different sensitivities. This implies that a careful interpretation of the time series acquired by the three sensor types is needed and that event parameters can only be compared relatively.

\subsection{AE/MS Response to Fracture Events, Rockfall, and Controlled Experiments}

Two distinct fracture events were detected prior to the 2015 rockfall with the fracture displacement monitoring system (crackmeter). Analyzing the AE/MS activity during this period enabled accurate time stamping of these events, but in contrast to other studies (Amitrano et al., 2005; Faillettaz et al., 2011), no change in statistical behavior of microseismicity was found. For both events, the signals were simultaneously recorded at the different measurement devices, but the characteristics (waveform, amplitude, etc.) differed substantially. The controlled rebound hammer experiment further investigated this discrepancy and led to two major findings.

First, statistically insignificant cross correlation between signals indicates that waveforms change strongly with propagation distance. We demonstrate in Figures 4 and 5 that these waves are strongly attenuated during the travel through the inhomogeneous rock mass. In accordance with theory, signals with high frequencies of short wavelength are more attenuated. This may be explained by the frequency-dependent exponent $\alpha$ [to the power of $e$, equation (2)] in combination with an increased scattering phenomenon and mode conversion at boundaries or interfaces in such heterogeneous fractured bedrock (see section 1.2).

Second, based on the characterization of artificially generated events, a significant amplification was found in the frequency band 33-67 Hz leading to an enhanced detection in this particular frequency band. This filter effect of the rock mass was estimated using the artificial rebound hammer experiment and supported by artificial rockfall events as well as natural fracture displacements. The amplification found between 33 and $67 \mathrm{~Hz}$ has important implications for event detection: it not only improves event detection of previously untriggered events but also removes false positives. We have no obvious explanation for such amplifying behavior in a narrow frequency band, but the evidence seems statistically sound. We envisage three potential explanations: (1) energy transformation or concentration in some frequency bands, (2) the phenomenon of acoustic resonance related to the geological structure with coincident damping in the upper frequencies due to frequency-dependent attenuation, and (3) a combination or mixture of wave types not being clearly assignable to body and surface waves.

A possible limitation of the rebound hammer experiment could be the coupling of the source with the rock mass. However, the estimation of the rock filter showed similar results for the path between Locations 1 and 2 , even if these two locations and the seismometer did not lie on the same line. The similarity in amplification for these propagation paths is not obvious, given that these paths are perpendicular to each other. This implies a negligible influence of the principal schistosity/cleavage on this amplification effect, as the two orthogonal 
propagation paths exhibit different spatial orientations with respect to the schistosity/cleavage. The fact that both propagation paths are on the same rock mass supports the explanation of rock mass resonance. The second type of experiment using rock fall impact further corroborates the above findings. In a nutshell, all impulse experiments at each location provided statistically sound evidence of this amplification behavior. These controlled experiments with artificial point sources turned out to be suitable for the characterization of waves propagating through steep, fractured bedrock permafrost. They further suggest that a broadband excitation at the artificial point source is more important than the detailed characteristics of the waveform of such signals, as the waveform strongly changes with propagation due to the frequency selective medium.

Analysis of naturally occurring fracture displacement events can be consistently detected when applying the filter derived from the artificial propagation experiments. It is not obvious whether the captured signal is the microseismic response to the fracture or to the impact of possibly falling rocks. But the analyzed microseismic response to fracture events indicates that the measured fracture displacement between two consecutive measurement points consists only of a single slip event. Nevertheless, it remains open whether this specific frequency band for amplification is site or location dependent and what the influence of the geological conditions is. Further research is needed to provide a clear answer here. Notably, hazard-related seismic activity in other media is observed in similar frequency ranges indicating that the filtering method could be transfered. For example, in glacier ice, the formation of surface crevasses results in icequakes with a seismic signal in the frequency range between 10 and $50 \mathrm{~Hz}$ (Deichmann et al., 2000; Mikesell et al., 2012; Neave \& Savage, 1970; Roux et al., 2008; Walter et al., 2008) characterized by a dominant Rayleigh wave and few or no visible $P$ and $S$ phase arrivals (Röösli et al., 2014).

\subsection{Implications on Fracture Detection in Different Frequency Domains}

Our study showed that $\mathrm{AE}$ data in the $\mathrm{kHz}$ range could only be used to monitor very local effects due to the strong attenuation. Hence, $A E$ is more suitable for monitoring initial cracking and microprocesses than for early warning purposes but requires preknowledge of the location where the cracking is expected to occur. Further, the AE system triggered multiple AE hits for one rebound hammer impulse. The reason for this is likely twofold: First, AEs usually occur in bursts and not as a single hit (Grosse \& Ohtsu, 2008). Second, the fixed threshold and the system-designed maximal recording duration may slice one larger, long event into several shorter ones. Interestingly, an increased activity was recorded at both $A E$ sensors $\left(A E_{\text {high }}\right.$ and $\left.A E_{l o w}\right)$ during the initial phase of enhanced fracture displacement measured approximately $4 \mathrm{~m}$ apart (gray bar in Figures $2 \mathrm{~b}$ and 2c). Although the link between fracture displacement and AE hits seems obvious, no evidence is provided.

In contrast to the AE records, the detection range of the MS is much larger as long as the source is strong enough to be distinguished from background seismicity, anthropogenic noise, and other sources. This distinction is a common and major problem for analyzing microseismic data. Our investigations therefore underline again the difficulties in interpreting MS signals themselves in steep, structured permafrost bedrock. Thus, experiments with a range of different forcing are needed to quantify the wide-scale attenuation and its influence on the detection of fracture events farther away.

The link between AE/MS signals and the specific forcing process in general is not straightforward. For instance, the recorded AE/MS signals could potentially have been generated by three different types of mechanical loading of rock, that is, constant (gravity), fluctuating (pressure variations in rock pores and cracks), and short-term (e.g., earthquakes or rockfalls) loads (Amitrano et al., 2012). For the analysis of the recorded fracture events, we interpreted the microseismic signal as the response to fracture although the only indication was the temporal coincidence of the microseismic signal with the observed fracture displacement or mass loss. Nevertheless, this would imply a link to the driver of fracture kinematics. In mountain permafrost, fracture kinematics is often related to (i) thermally induced stress, (ii) pressure evolving in ice-filled fractures or pores, and (iii) water-related destabilization (Weber et al., 2017). While thermally induced stress-causing rock fracture acts either by repetitive low-magnitude temperature cycles leading to thermal stress fatigue or by rapid temperature change (Murton, 2007), frost cracking yields stronger damage under sustained freezing conditions than repeated freeze-thaw cycling (Girard et al., 2013). In the long term, fatigue processes due to periodic loading of discontinuities can lead to enhanced displacement (Gischig et al., 2011) driven by the culmination of progressive damage in heterogeneous natural materials (Faillettaz \& Or, 2015). However, the identification of fracture events in the AE/MS signals without complementary surface displacement measurements is not possible, because the $\mathrm{AE} / \mathrm{MS}$ response to fracture does not exhibit a distinctive characteristic due to its change with propagation. 
Acknowledgments

The work presented in this paper is part of the project $X$-Sense 2 and was financed by http://www.nano-tera.ch (ref. 530659). We thank CERN for Zenodo service hosting data supporting the conclusions (Weber et al., 2018) and publishing the analysis code (Weber \& Meyer, 2018). We are grateful to Stephan Gruber and Lucas Girard for laying the cornerstone of this project by writing major elements of the project proposal. We acknowledge the PermaSense team, especially Tonio Gsell, who provided valuable support with the development of measurement devices and with data management. We thank Andreas Hasler for support with the experiment design and installation, Lukas Preiswerk and Valentin Gischig for valuable feedback, and Ernest Lotter from the Institute of Mine Seismology for remarkable support in the acquisition and processing of the accelerometer data. We are grateful to Ross Purves and Marius Büchi for constructive comments and discussion. We thank Simon Allen for editing the English. Reviews from Stuart Dunning, and an anonymous referee provided valuable comments that helped to improve the paper substantially. Finally, we thank the handling Editors Bryn Hubbard and Giovanni Coco for constructive feedback and suggestions. Samuel Weber in collaboration with all coauthors designed the field

experiment. Samuel Weber and Jan Beutel installed the sensors in 2015 and have done maintenance work and data management as well as processing. The analysis code in Python 3 was written by Samuel Weber with support in signal processing by Matthias Meyer. Samuel Weber prepared the manuscript with contribution of all coauthors. The authors declare that they have no conflict of interest.

\subsection{Implications for Early Warning}

Only a few single fracture displacements and small rockfall events have been observed by the multimodal monitoring setup consisting of crackmeter, time lapse camera, and AE/MS sensors (Figure 1). Thus, the occurrence of precursory signals prior to larger rock slope failures remains unclear in such fractured bedrock. Analyzing and interpreting AE/MS data correctly and performing the instrumentation and monitoring under such extreme environmental conditions constitutes a main challenge.

Nevertheless, this work demonstrates the feasibility of long-term monitoring deployment and the 2-year time series provides the ground truth data, which potentially enables the identification of a statistical precursor for future rock slope failure. As discussed in section 4, anthropogenic activity (see section 2.1) impedes our analysis, but considering only night hours in our time series resolves this issue. Interestingly, the seasonal varying baseline offset remains, but time dependence can be removed with appropriate filtering (see section 4.2). Removing anthropogenic disturbance would enable us to perform an in-depth study of the possible link between AE/MS activity and all these processes for the general case. This would constitute a further step toward identification of possible precursory signs of impending failure. From the general context of early warning analysis, an unbiased MS catalog is a prerequisite to improve understanding of the processes which lead to irreversible fracture displacement, potentially precondition rock slope instabilities (Weber et al., 2017), or to perform stability assessment using event-based statistical analysis, for example, evolution of the probability density function before failure (Amitrano et al., 2005).

\section{Conclusion and Further Work}

In this study, AE/MS activity was monitored in high mountain bedrock permafrost during a period of 2 years. Although technically challenging, we managed to capture for the first time the AE/MS activity in a frequency band ranging from 1 to $10^{5} \mathrm{~Hz}$. In addition to passive monitoring, we also performed active measurements using a rebound hammer and rock drop as point sources to simulate surface detachment events. Based on these controlled experiments, we demonstrate a strong attenuation of the propagating waveform at high frequencies and a strong change in waveform characteristics during propagation, which disables feature detection by cross correlation. Furthermore, a signal amplification in the frequency band 33-67 $\mathrm{Hz}$ was observed. The origins of this phenomenon remain uncertain, and it is not clear whether this frequency band of amplification is site/location dependent or is a general characteristic for fractured bedrock conditions and therefore transferable to other sites.

We demonstrated that band-pass filtering raw data in this frequency band helps to automatically detect not only artificial but also naturally occurring events: Seismic events recorded during fracture displacements were detected much more reliably and on all three components in the filtered band. Furthermore, our analysis of the 2-year time series suggested that filtering raw data in this frequency band might be a first important step toward the constitution of an unbiased catalog of microseismic events. Indeed, the energy rate baseline of the triggered events in this frequency band is no longer sensitive to positive temperature values. This is essential for data analysis, result interpretation, and preventing misinterpretation, in particular, for studies investigating the response to environmental forcing.

In summary, our study provides a better understanding of signal propagation in steep, structured bedrock permafrost. The transfer of the proposed filtering band to the time series allows an improved detection of naturally occurring fracture events. This provides a basis for future investigation of the fracture mechanism-based AE/MS data. However, the occurrence of microseismic events caused by anthropogenic noise remains and further efforts are needed on labeling and eventually distinguishing anthropogenic activity from bedrock internal activity. The analysis of the continuous waveform, for example, ambient seismic noise correlograms (Mainsant et al., 2012) or polarization of particle motion (Burjánek et al., 2014, 2018), might successfully complement the event-based analysis, as automatically triggered events using an STA/LTA algorithm strongly depend on the setting of the trigger parameters.

\section{References}

Alava, M. J., Nukala, P. K. V. V., \& Zapperi, S. (2006). Statistical model of fracture. Advances in Physics, 55(3-4), 349-476. https://doi.org/10.1080/00018730300741518

Amitrano, D., Arattano, M., Chiarle, M., Mortara, G., Occhiena, C., Pirulli, M., \& Scavia, C. (2010). Microseismic activity analysis for the study of the rupture mechanisms in unstable rock masses. Natural Hazards and Earth System Sciences, 10(4), 831-841. https://doi.org/10.5194/nhess-10-831-2010 
Amitrano, D., Grasso, J., \& Senfaute, G. (2005). Seismic precursory patterns before a cliff collapse and critical point phenomena. Geophysical Research Letters, 32, L08314. https://doi.org/10.1029/2004GL022270

Amitrano, D., Gruber, S., \& Girard, L. (2012). Evidence of frost-cracking inferred from acoustic emissions in a high-alpine rock-wall. Earth and Planetary Science Letters, 341, 86-93. https://doi.org/10.1016/j.epsl.2012.06.014

Arosio, D., Longoni, L., Papini, M., Scaioni, M., Zanzi, L., \& Alba, M. (2009). Towards rockfall forecasting through observing deformations and listening to microseismic emissions. Natural Hazards and Earth System Science, 9, 1119-1131. https://doi.org/10.5194/nhess-9-1119-2009

Ashford, S. A., Sitar, N., Lysmer, J., \& Deng, N. (1997). Topographic effects on the seismic response of steep slopes. Bulletin of the Seismological Society of America, 87(3), $701-709$.

Beutel, J., Gruber, S., Hasler, A., Lim, R., Meier, A., Plessl, C., et al. (2009). PermaDAQ: A scientific instrument for precision sensing and data recovery in environmental extremes. In The 8Th ACM/IEEE International Conference on Information Processing in Sensor Networks, San Francisco, California, USA, pp. 265-276.

Blikra, L. H., \& Christiansen, H. H. (2014). A field-based model of permafrost-controlled rockslide deformation in Northern Norway. Geomorphology, 208, 34-39. https://doi.org/10.1016/j.geomorph.2013.11.014

Bucher, K., Dal Piaz, G. V., Oberhänsli, R., Gouffon, Y., Martinotti, G., \& Polino, R. (2004). Blatt 1347, Matterhorn. Geol. Atlas Schweiz 1:25 000, Erläut 107. Wabern: Bundesamt für Wasser und Geologie.

Burjánek, J., Edwards, B., \& Fäh, D. (2014). Empirical evidence of local seismic effects at sites with pronounced topography: A systematic approach. Geophysical Journal International, 197(1), 608-619. https://doi.org/10.1093/gji/ggu014

Burjánek, J., Gischig, V., Moore, J. R., \& Fäh, D. (2018). Ambient vibration characterization and monitoring of a rock slope close to collapse. Geophysical Journal International, 212(1), 297-310. https://doi.org/10.1093/gji/ggx424

Cohen, D., Lehmann, P., \& Or, D. (2009). Fiber bundle model for multiscale modeling of hydromechanical triggering of shallow landslides. Water Resources Research, 45, W10436. https://doi.org/10.1029/2009WR007889

Dammeier, F., Moore, J. R., Haslinger, F., \& Loew, S. (2011). Characterization of alpine rockslides using statistical analysis of seismic signals. Journal of Geophysical Research, 116, F04024. https://doi.org/10.1029/2011JF002037

Deichmann, N., Ansorge, J., Scherbaum, F., Aschwanden, A., Bernardi, F., \& Gudmundsson, G. H. (2000). Evidence for deep icequakes in an alpine glacier. Annals of Glaciology, 31, 85-90. https://doi.org/10.3189/172756400781820462

Del Gaudio, V., Muscillo, S., \& Wasowski, J. (2014). What we can learn about slope response to earthquakes from ambient noise analysis: An overview. Engineering Geology, 182(Part B), 182-200. https://doi.org/10.1016/j.enggeo.2014. 05.010

Dietze, M., Mohadjer, S., Turowski, J. M., Ehlers, T. A., \& Hovius, N. (2017). Seismic monitoring of small alpine rockfalls - Validity, precision and limitations. Earth Surface Dynamics, 5(4), 653-668. https://doi.org/10.5194/esurf-5-653-2017

Dixon, N., Hill, R., \& Kavanagh, J. (2003). Acoustic emission monitoring of slope instability: Development of an active waveguide system. Proceedings of the Institution of Civil Engineers - Geotechnical Engineering, 156, 83-95. https://doi.org/10.1680/geng.2003.156.2.83

Dixon, N., Smith, A., Spriggs, M., Ridley, A., Meldrum, P., \& Haslam, E. (2015). Stability monitoring of a rail slope using acoustic emission. Proceedings of the Institution of Civil Engineers - Geotechnical Engineering, 168(5), 373-384. https://doi.org/10.1680/jgeen.14.00152

Dobrin, M. (1960). Introduction to geophysical prospecting. Geophysical Journal International, 3(3), 378-379. https://doi.org/10.1093/gji/3.3.378

Draebing, D., \& Krautblatter, M. (2012). P-wave velocity changes in freezing hard low-porosity rocks: A laboratory-based time-average model. The Cryosphere, 6, 1163-1174.

Draebing, D., Krautblatter, M., \& Hoffmann, T. (2017). Thermo-cryogenic controls of fracture kinematics in permafrost rockwalls. Geophysical Research Letters, 44, 3535-3544. https://doi.org/10.1002/2016GL072050

Duca, S., Occhiena, C., Mattone, M., Sambuelli, L., \& Scavia, C. (2014). Feasibility of ice segregation location by acoustic emission detection: A laboratory test in gneiss. Permafrost and Periglacial Processes, 25(3), 208-219. https://doi.org/10.1002/ppp.1814

Eberhardt, E., Stead, D., \& Coggan, J. (2004). Numerical analysis of initiation and progressive failure in natural rock slopes - The 1991 Randa rockslide. International Journal of Rock Mechanics and Mining, 41(1), 69-87. https://doi.org/10.1016/S1365-1609(03)00076-5

Eberhardt, E., Watson, A. D., \& Löw, S. (2008). Improving the interpretation of slope monitoring and early warning data through better understanding of complex deep-seated landslide failure mechanisms. In Z. Chen, J. Zhang, Z. Li, \& F. Wu (Eds.), Landslides and Engineered Slopes: From the Past to the Future (pp. 39-51). London, UK: Taylor \& Francis Group. https://doi.org/10.1201/9780203885284-c3

Erismann, T. H., \& Abele, G. (2001). Dynamic of rockslides and rockfalls. New York: Springer-Verlag Berlin Heidelberg. https://doi.org/10.1007/978-3-662-04639-5

Evans, A. G. (1979). Acoustic emission sources in brittle solids. In K. Ono (Ed.), Fundamentals of acoustic emission (pp. 209-227). Los Angeles: University of California.

Faillettaz, J., \& Or, D. (2015). Failure criterion for materials with spatially correlated mechanical properties. Physical Review E, 91 (3), 032134. https://doi.org/10.1103/PhysRevE.91.032134

Faillettaz, J., Or, D., \& Reiweger, I. (2016). Codetection of acoustic emissions during failure of heterogeneous media: New perspectives for natural hazard early warning. Geophysical Research Letters, 43, 1075-1083. https://doi.org/10.1002/2015GL067435

Faillettaz, J., Pralong, A., Funk, M., \& Deichmann, N. (2008). Evidence of log-periodic oscillations and increasing icequake activity during the breaking-off of large ice masses. Journal of Glaciology, 54(187), 725-737. https://doi.org/10.3189/002214308786570845

Faillettaz, J., Sornette, D., \& Funk, M. (2011). Icequakes coupled with surface displacements for predicting glacier break-off. Journal of Glaciology, 57(203), 453-460. https://doi.org/10.3189/002214311796905668

Gibbons, S. J., \& Ringdal, F. (2006). The detection of low magnitude seismic events using array-based waveform correlation. Geophysical Journal International, 165(1), 149-166. https://doi.org/10.1111/j. 1365-246\$ \times\$.2006.02865.x

Girard, L., Beutel, J., Gruber, S., Hunziker, J., Lim, R., \& Weber, S. (2012). A custom acoustic emission monitoring system for harsh environments: application to freezing-induced damage in alpine rock walls. Geoscientific Instrumentation Methods and Data Systems, 1(2), 155-167. https://doi.org/10.5194/gi-1-155-2012

Girard, L., Gruber, S., Weber, S., \& Beutel, J. (2013). Environmental controls of frost cracking revealed through in-situ acoustic emission measurements in steep bedrock. Geophysical Research Letters, 40, 1748-1753. https://doi.org/10.1002/grl.50384

Gischig, V., Moore, J. R., Evans, K., Amann, F., \& Loew, S. (2011). Thermomechanical forcing of deep rock slope deformation: 1. Conceptual study of a simplified slope. Journal of Geophysical Research, 116, F04010. https://doi.org/10.1029/2011JF002006

Got, J.-L., Mourot, P., \& Grangeon, J. (2010). Pre-failure behaviour of an unstable limestone cliff from displacement and seismic data. Natural Hazards and Earth System Sciences, 10(4), 819-829. https://doi.org/10.5194/nhess-10-819-2010

Grosse, U. C., \& Ohtsu, M. (2008). Acoustic emission testing: Basics for research-Aplications in civil engineering (chap. Introduction, pp. 3-10). Berlin: Springer-Verlag.

Gruber, S., \& Haeberli, W. (2007). Permafrost in steep bedrock slopes and its temperature-related destabilization following climate change. Journal of Geophysical Research, 112, F02S18. https://doi.org/10.1029/2006JF000547 
Hallet, B., Walder, J., \& Stubbs, C. (1991). Weathering by segregation ice growth in microcracks at sustained subzero temperatures: Verification from an experimental study using acoustic emissions. Permafrost and Periglacial Process., 2(4), $283-300$. https://doi.org/10.1002/ppp.3430020404

Hardy, H. R. (2003). Acoustic emission/microseismic activity_Volume 1: Principles, techniques and geotechnical applications. Lisse, Netherlands: A.A. Balkema Publisher, a member of Swets \& Zeitlinger Publishers.

Hasler, A., Gruber, S., \& Beutel, J. (2012). Kinematics of steep bedrock permafrost. Journal of Geophysical Research, 117, F01016. https://doi.org/10.1029/2011JF001981

Hasler, A., Gruber, S., \& Haeberli, W. (2011). Temperature variability and offset in steep alpine rock and ice faces. The Cryosphere, 5, 977-988. https://doi.org/10.5194/tc-5-977-2011

Hasler, A., Talzi, I., Beutel, J., Tschudin, C., \& Gruber, S. (2008). Wireless sensor networks in permafrost research: Concept, requirements, implementation, and challenges. In Proceedings of the 9Th International Conference on Permafrost 2008, Fairbanks, Alaska (pp. 669-674).

Hidalgo, R. C., Moreno, Y., Kun, F., \& Herrmann, H. J. (2002). Fracture model with variable range of interaction. Physical Review E, 65, 046148. https://doi.org/10.1103/PhysRevE.65.046148

Holland, A. A. (2013). Earthquakes triggered by hydraulic fracturing in South-Central Oklahoma. Bulletin of the Seismological Society of America, 103(3), 1784-1792. https://doi.org/10.1785/0120120109

Kleinbrod, U., Burjánek, J., \& Fäh, D. (2017). From ambient vibration assessment of potential rock slope instabilities to earthquake triggered rockslides. In 16th World conference on earthquake engineering (pp. 2216).

Knopoff, L., \& Gangi, A. F. (1959). Seismic reciprocity. Geophysics, 24(4), 681-691. https://doi.org/10.1190/1. 1438647

Krautblatter, M., Funk, D., \& Günzel, F. (2013). Why permafrost rocks become unstable: A rock-ice-mechanical model in time and space. Earth Surface Processes and Landforms, 38(8), 876-887. https://doi.org/10.1002/esp.3374

Krischer, L., Megies, T., Barsch, R., Beyreuther, M., Lecocq, T., Caudron, C., \& Wassermann, J. (2015). ObsPy: A bridge for seismology into the scientific Python ecosystem. Computational Science \& Discovery, 8(1), 014003. https://doi.org/10.1088/1749-4699/8/1/014003

Kun, F., Moreno, Y., Hidalgo, R. C., \& Herrmann, H. J. (2003). Creep rupture has two universality classes. Europhysics Letters, 63(3), $347-353$.

LeBlanc, D. (2004). Statistics: Concepts and applications for science, band 2 ed, vol. 2: Jones and Bartlett Publishers, Sudbury, Massachusetts, United States.

Lévy, C., Baillet, L., Jongmans, D., Mourot, P., \& Hantz, D. (2010). Dynamic response of the chamousset rock column (western Alps, France). Journal of Geophysical Research, 115, F04043. https://doi.org/10.1029/2009JF001606

Lockner, D. (1993). The role of acoustic emission in the study of rock. International Journal of Rock Mechanics and Mining Science \& Geomechanics Abstracts, 30(7), 883-899.

Lockner, D. A., Byerlee, J. D., Kuksenko, V., Ponomarev, A., \& Sidorin, A. (1991). Quasi-static fault growth and shear fracture energy in granite. Nature, 350, 39-42. https://doi.org/10.1038/350039a0

Mainsant, G., Larose, E., Brönnimann, C., Jongmans, D., Michoud, C., \& Jaboyedoff, M. (2012). Ambient seismic noise monitoring of a clay landslide: Toward failure prediction. Journal of Geophysical Research, 117, F01030. https://doi.org/10.1029/2011JF002159

Mamot, P., Weber, S., Schröder, T., \& Krautblatter, M. (2018). A temperature- and stress-controlled failure criterion for ice-filled permafrost rock joints. The Cryosphere Discussions. https://doi.org/10.5194/tc-2018-57

Matsuoka, N., \& Murton, J. (2008). Frost weathering: Recent advances and future directions. Permafrost and Periglacial Process., 19(2), 195-210. https://doi.org/10.1002/ppp.620

Michlmayr, G., Cohen, D., \& Or, D. (2012). Sources and characteristics of acoustic emissions from mechanically stressed geologic granular media -A review. Earth-Science Reviews, 112(3-4), 97-114. https://doi.org/10.1016/j.earscirev. 2012.02.009

Mikesell, T. D., van Wijk, K., Haney, M. M., Bradford, J. H., Marshall, H. P., \& Harper, J. T. (2012). Monitoring glacier surface seismicity in time and space using Rayleigh waves. Journal of Geophysical Research, 117, F02020. https://doi.org/10.1029/2011JF002259

Moore, J., Gischig, V., Amann, F., Hunziker, M., \& Burjánek, J. (2012). Earthquake-triggered rock slope failures: Damage and site effects. In E. Eberhardt, C. Froese, K. Turner, \& S. Leroueil (Eds.), Proceedings 11th International \& 2nd North American Symposium on Landslides (Vol. 1, pp. 869-875). Banff, Canada: CRC Press.

Moore, J., Gischig, V., Burjánek, J., Loew, S., \& Fäh, D. (2011). Site effects in unstable rock slopes: Dynamic behavior of the Randa instability (Switzerland). Bulletin of the Seismological Society of America, 101(6), 3110-3116. https://doi.org/10.1785/0120110127

Murton, J. (2007). Rock Weathering. In S. Elias \& C. Mock (Eds.), Encyclopedia of quaternary science (Vol. 1, pp. 2249-2256). Oxford: Elsevier

Murton, J., Kuras, O., Krautblatter, M., Cane, T., Tschofen, D., Uhlemann, S., et al. (2016). Monitoring rock freezing and thawing by novel geoelectrical and acoustic techniques. Journal of Geophysical Research: Earth Surface, 121(12), $2309-2332$. https://doi.org/10.1002/2016JF003948

Murton, J., Peterson, R., \& Ozouf, J.-C. (2006). Bedrock fracture by ice segregation in cold regions. Science, 314(5802), 1127-1129. https://doi.org/10.1126/science.1132127

Neave, K. G., \& Savage, J. C. (1970). Icequakes on the Athabasca glacier. Journal of Geophysical Research, 75(8), 1351-1362. https://doi.org/10.1029/JB075i008p01351

Nordvik, T., Blikra, L. H., Nyrnes, E., \& Derron, M.-H. (2010). Statistical analysis of seasonal displacements at the Nordnes rockslide, Northern Norway. Engineering Geology, 114(3-4), 228-237. https://doi.org/10.1016/j.enggeo. 2010.04.019

Obert, L. (1977). The microseismic method: Discovery and early history. In Proceedings First Conference on Acoustic Emission/Microseismic Activity in Geologic Structures and Materials, Clausthal-Zellerfeld, Germany (pp. 11-12) .

ObsPy, T. (2017). ObsPy: A Python toolbox for seismology/seismological observatories. https://doi.org/10.5281/zenodo.165134

Occhiena, C., Coviello, V., Arattano, M., Chiarle, M., Morra di Cella, U., Pirulli, M., et al. (2012). Analysis of microseismic signals and temperature recordings for rock slope stability investigations in high mountain areas. Natural Hazards and Earth System Science, 12(7), $2283-2298$. https://doi.org/10.5194/nhess-12-2283-2012

Ohnaka, M., \& Mogi, K. (1982). Frequency characteristics of acoustic emission in rocks under uniaxial compression and its relation to the fracturing process to failure. Journal of Geophysical Research, 87(B5), 3873-3884. https://doi.org/10.1029/JB087iB05p03873

PERMOS (2016). Permafrost in Switzerland 2010/2011 to 2013/2014. In J. Noetzli, R. Luethi, \& B. Staub (Eds.), Glaciological Report Permafrost No. 12-15 of the Cryospheric Commission of the Swiss Academy of Sciences (p. 85).

Peters, L., Anandakrishnan, S., Alley, R., \& Voigt, D. (2012). Seismic attenuation in glacial ice: A proxy for englacial temperature. Journal of Geophysical Research, 117, F02008. https://doi.org/10.1029/2011JF002201

Petley, D. N. (2004). The evolution of slope failures: Mechanisms of rupture propagation. Natural Hazards and Earth System Science, 4(1), 147-152. https://doi.org/10.5194/nhess-4-147-2004

Pleuger, J., Roller, S., Walter, J. M., Jansen, E., \& Froitzheim, N. (2007). Structural evolution of the contact between two penninic nappes (Zermatt-Saas zone and Combin zone, Western Alps) and implications for the exhumation mechanism and palaeogeography. International Journal of Earth Sciences, 96(2), 229-252. https://doi.org/10.1007/s00531-006-0106-6 
Podolskiy, E. A., \& Walter, F. (2016). Cryoseismology. Reviews of Geophysics, 54, 708-758. https://doi.org/10.1002/2016RG000526 Pradhan, S., Hansen, A., \& Chakrabarti, B. K. (2010). Failure processes in elastic fiber bundles. Reviews of Modern Physics, 82, $499-555$. https://doi.org/10.1103/RevModPhys.82.499

Pradhan, S., Hansen, A., \& Hemmer, P. C. (2005). Crossover behavior in burst avalanches: Signature of imminent failure. Physical Review Letters, 95, 125501. https://doi.org/10.1103/PhysRevLett.95.125501

Proceq (2017). Portable non-destructive concrete testing instruments. Sales flyer, Proceq SA Switzerland.

Reiweger, I., Mayer, K., Steiner, K., Dual, J., \& Schweizer, J. (2015). Measuring and localizing acoustic emission events in snow prior to fracture. Cold Regions Science and Technology, 110, 160-169. https://doi.org/10.1016/j.coldregions.2014.12.002

Rinehart, J. S. (1975). Stress transients in solids (Vol. 1, pp. 230). Santa Fe: HyperDynamics.

Röösli, C., Walter, F., Husen, S., Andrews, L. C., Lüthi, M. P., Catania, G. A., \& Kissling, E. (2014). Sustained seismic tremors and icequakes detected in the ablation zone of the Greenland ice sheet. Journal of Glaciology, 60(221), 563-575. https://doi.org/10.3189/2014JoG13J210

Rosser, N., Lim, M., Petley, D., Dunning, S., \& Allison, R. (2007). Patterns of precursory rockfall prior to slope failure. Journal of Geophysical Research, 112, F04014. https://doi.org/10.1029/2006JF000642

Roux, P.-F., Marsan, D., Métaxian, J.-P., O'Brien, G., \& Moreau, L. (2008). Microseismic activity within a serac zone in an alpine glacier (Glacier d'Argentiere, Mont Blanc, France). Journal of Glaciology, 54, 157-168. https://doi.org/10.3189/002214308784409053

Scholz, C. (1968). Microfracturing and the inelastic deformation of rock in compression. Journal of Geophysical Research, 73(4), $1417-1432$. https://doi.org/10.1029/JB073i004p01417

Smith, A., Dixon, N., \& Fowmes, G. J. (2017). Early detection of first-time slope failures using acoustic emission measurements: Large-scale physical modelling. Géotechnique, 67(2), 138-152. https://doi.org/10.1680/jgeot.15.P.200

Spillmann, T., Maurer, H., Green, A. G., Heincke, B., Willenberg, H., \& Husen, S. (2007). Microseismic investigation of an unstable mountain slope in the Swiss Alps. Journal of Geophysical Research, 112, B07301. https://doi.org/10.1029/2006JB004723

Stähli, M., Sättele, M., Huggel, C., McArdell, B. W., Lehmann, P., Van Herwijnen, A., et al. (2015). Monitoring and prediction in early warning systems for rapid mass movements. Natural Hazards and Earth System Science, 15(4), 905-917. https://doi.org/10.5194/nhess-15-905-2015

Szwedzicki, T. (2003). Rock mass behaviour prior to failure. International Journal of Rock Mechanics and Mining, 40, $573-584$.

Van Herwijnen, A., \& Schweizer, J. (2011). Seismic sensor array for monitoring an avalanche start zone: Design, deployment and preliminary results. Journal of Glaciology, 57(202), 267-276. https://doi.org/10.3189/002214311796405933

Walter, F., Deichmann, N., \& Funk, M. (2008). Basal icequakes during changing subglacial water pressures beneath Gornergletscher, Switzerland. Journal of Glaciology, 54(186), 511-521. https://doi.org/10.3189/002214308785837110

Weber, S., Beutel, J., Faillettaz, J., Hasler, A., Krautblatter, M., \& Vieli, A. (2017). Quantifying irreversible movement in steep, fractured bedrock permafrost on Matterhorn (CH). The Cryosphere, 11(1), 567-583. https://doi.org/10.5194/tc-11-567-2017

Weber, S., Beutel, J., Gruber, S., Gsell, T., Hasler, A., \& Vieli, A. (2018). Rock-temperature, fracture displacement and acoustic/micro-seismic data measured at Matterhorn Hörnligrat. Switzerland. https://doi.org/10.5281/zenodo.1163037

Weber, S., Gruber, S., Girard, L., \& Beutel, J. (2012). Design of a measurement assembly to study in situ rock damage driven by freezing In K. M. Hinkel (Ed.), In proceedings of the 10th International Conference on Permafrost (Vol. 1, pp. 437-442). Salekhard, Russia: The Northern Publisher.

Weber, S., \& Meyer, M. (2018). Python3 code for the analysis of acoustic and micro-seismic data measured at Matterhorn Hörnligrat. Switzerland. https://doi.org/10.5281/zenodo.1215643

Wegmann, M., \& Gudmundsson, G. H. (1999). Thermally induced temporal strain variations in rock walls observed at subzero temperatures. In K. Hutter, Y. Wang, \& H. Beer (Eds.), Advances in cold-region thermal engineering and sciences (Vol. 533, pp. 511-518). Berlin: Springer. https://doi.org/10.1007/BFb0104208

Withers, M., Aster, R., Young, C., Beiriger, J., Harris, M., Moore, S., \& Trujillo, J. (1998). A comparison of select trigger algorithms for automated global seismic phase and event detection. Bulletin of the Seismological Society of America, 88(1), 95-106.

Zoppè, G., Costa, G., Dixon, N., Spriggs, M. P., \& Marcato, G. (2015). Microseismicity and acoustic emission for landslide monitoring (Northeast Italy). (pp. 1527-1530). Cham: Springer International Publishing. https://doi.org/10.1007/978-3-319-09057-3_270 